\title{
Activation of LXR $\beta$ Signaling in the Amygdala Confers Anxiolytic Effects Through Rebalancing Excitatory and Inhibitory Neurotransmission upon Acute Stress
}

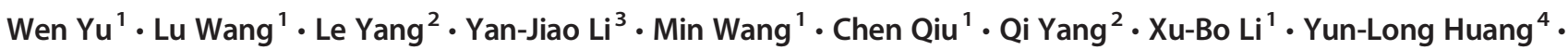 \\ Rui Liu $^{5} \cdot$ Yu-Mei Wu ${ }^{1}$
}

Published online: 15 April 2020

(C) The American Society for Experimental NeuroTherapeutics, Inc. 2020

\begin{abstract}
The balance of major excitatory (glutamate, Glu) and inhibitory ( $\gamma$-aminobutyric acid, GABA), named as E/I neurotransmission, is critical for proper information processing. Anxiety-like responses upon stress are accompanied by abnormal alterations in the formation and function of synapses, resulting in the imbalance of E/I neurotransmission in the amygdala. Liver X receptors (LXRs), including LXR $\alpha$ and LXR $\beta$ isoforms, are nuclear receptors responsible for regulating central nervous system (CNS) functions besides maintaining metabolic homeostasis. However, little is known about the contribution of LXRs in E/I balance in regulating anxiety-related behaviors induced by stress. In this study, we found stress-induced anxiety led to the expression reduction of LXR $\beta$ not LXR $\alpha$ in mice amygdala. GW3965, a dual agonist for both LXR $\alpha$ and LXR $\beta$, alleviated anxiety-like behaviors of stressed mice through activation of $\operatorname{LXR} \beta$, confirmed by the knockdown of LXR $\beta$ mediated by lentiviral shRNAs in the basolateral amygdala (BLA). This was paralleled by correcting the disequilibrium of E/I neurotransmission in the stressed BLA. Importantly, GW3965 exerted anxiolytic effects by correcting the promoted amplitude and frequency of miniature excitatory postsynaptic current (mEPSC), and augmenting the decreased that of miniature inhibitory postsynaptic current (mIPSC) in the stressed BLA. This suggests that stress-induced anxiety-like behaviors can largely be ascribed to the deficit of LXR $\beta$ signaling in E/I neurotransmission in BLA. These findings highlight the deficiency of LXR $\beta$ signaling in the amygdala linked to anxiety disorder, and LXR $\beta$ activation may represent a potential novel target for anxiety treatment with an alteration in synaptic transmission in the amygdala.
\end{abstract}

Key Words Liver X receptors · E/I neurotransmission $\cdot$ amygdala $\cdot$ anxiety $\cdot$ GW3965

Wen Yu, Lu Wang and Le Yang contributed equally to this work.

Electronic supplementary material The online version of this article (https://doi.org/10.1007/s13311-020-00857-y) contains supplementary material, which is available to authorized users.

Rui Liu

speciallr@163.com

Yu-Mei Wu

yumeiwu@fmmu.edu.cn

1 Department of Pharmacology, School of Pharmacy, Fourth Military Medical University, Xi'an 710032, Shaanxi Province, People's Republic of China

2 Department of Pharmacy, Tangdu Hospital, Fourth Military Medical University, Xi'an 710038, Shaanxi Province, People's Republic of China
3 Department of Acupuncture and Moxibustion, Xi'an Hospital of Traditional Chinese Medicine, Xi'an 710021, Shaanxi Province, People's Republic of China

4 Department of Pharmacology \& Experimental Neuroscience, University of Nebraska Medical Center, Omaha, NE 68198, USA

5 Department of Rehabilitation Medicine, Tangdu Hospital, Fourth Military Medical University, Xi'an 710032, Shaanxi Province, People's Republic of China 


\section{Introduction}

Severe or continued stress leads to multifaceted maladaptations ranging from gene modulation to synaptic dysfunction, which may account for the increased risk of developing neuropsychiatric disorders like anxiety, depression, and schizophrenia [1]. Among all stress-related neuropsychiatric disorders, anxiety disorders are the most common mental disorders, which affect nearly 1 in 5 adults in the USA alone [2]. The clinical manifestations of anxiety disorder are persistent anxiety, tension, panic and anxiety, accompanied by autonomic nervous system disorders, learning and memory decline and other symptoms. Yet, the precise mechanisms underlying stress-related behavioral disorders still remain open. Stress alters emotional and behavioral states significantly leading to numerous long-lasting adaptive changes in stress-sensitive brain regions, including the medial prefrontal cortex (mPFC), anterior cingulate cortex, frontopolar cortex, and amygdala $[3,4]$. The importance of the amygdala in stress response has been highlighted from studies in both animal models $[4,5]$ and patients with mood disorder [6]. Amygdala exhibits entire disparate functional and structural alterations under acute or chronic stress, characterized as hyperactivated or hyperreactive [7, 8]. Among the subregion of the amygdala, basolateral amygdala (BLA) occupies a kernel part of this system as well as a known involvement in stressinduced negative emotion. BLA is critical in the neural circuitry responsible for the regulation of affective behaviors, including anxiety, aggression, and social recognition, and integrates different modes of information flow from the lateral amygdala to the central amygdala [9] and elicits a series of stress responses, particularly in the process of anxiety [10]. Moreover, the BLA receives dense projections from the hippocampus as part of the septo-hippocampal axis, which is considered as a major regulator of anxiety-related behavior [11, 12].

It has been confirmed that overactivation of the hypothalamic-pituitary-adrenal (HPA) axis, dysfunction of cell signaling pathway, and disorder of neurotransmitters contributed to the emergence of anxiety disorder. As the two most important neurotransmitters in the central nervous system (CNS), glutamate (Glu) and $\gamma$-aminobutyric acid (GABA) mediate excitatory and inhibitory (E/I) neurotransmission, respectively, and the balance of E/I synaptic transmission is critical for proper information processing [11]. The disturbance of E/I balance underlies many neuropsychiatric illnesses, including autism spectrum disorder and schizophrenia, as well as anxiety. BLA is mainly composed of excitatory projection neurons and a small number of local inhibitory neurons. The glutamatergic neurons are firmly regulated by a comparatively small population of GABAergic inhibitory neurons within the amygdala [13]. Destruction of GABAergic inhibition in BLA can cause behavioral hyperexcitability, such as increased anxiety and depression, emotional dysregulation, and development of seizure activity [11]. The modulation of emotional responses by BLA is mainly determined by the $\mathrm{E} / \mathrm{I}$ balance inputs to its dominated neurons which are tightly controlled by GABAergic interneurons [13]. Notably, the prolonged disturbance of this balance between E/I transmission promotes pathological anxiety-like behaviors [14]. In the state of anxiety, inhibitory neurons in the BLA continue to increase their discharge, suggesting these GABAergic neurons are hence adequately positioned to play a central role in stress regulation. Therefore, resetting up the E/ I balance in the amygdala under stress may exert anxiolytic effects. It is worth exploring the specific molecular mechanisms underlying how acute stress affects the amygdala.

Liver X receptors (LXRs), including LXR $\alpha$ and LXR $\beta$ isoforms, belong to the nuclear receptor superfamily as transcription factors [15]. LXR $\alpha$ plays a significant role in cholesterol homeostasis, whereas LXR $\beta$ is involved in various brain functions. LXR $\alpha$ knockout did not induce fundamental development deficits in mice, whereas LXR $\beta$ deletion led to impaired cerebral cortex lamination [16] and neurodegeneration in the substantia nigra [17]; especially, female mice with LXR $\beta$ knockout $\left(\operatorname{LXR} \beta^{-/}\right)$showed an anxiety phenotype [18]. However, the roles and mechanisms of LXR $\beta$ in the stressed BLA remain unknown. This study aimed to investigate the possible anxiolytic effects of LXRs and to elucidate the underlying mechanisms. We report that acute stress resulted in the reduction of LXR $\beta$ expression in the amygdala. LXR $\beta$ activation by GW3965 (GW), a dual agonist for LXRs, attenuated the acute stress-induced anxiety-like behaviors, by regulating neurotransmitter release and receptor expression in BLA. Furthermore, GW reset the equilibrium between GABAergic and glutamatergic transmission, by decreasing the enhancive amplitude and frequency of mEPSC and increasing the attenuation of IPSC in BLA neurons after stress exposure. Collectively, our results reveal a major contribution of LXR $\beta$ in the BLA's key E/I neurotransmitter system in the regulation of anxiety behaviors, which is crucial to our understanding of the molecular mechanisms underlying anxiety disorders.

\section{Materials and Methods}

\section{Materials}

Anti-LXR $\beta$ (ab28479), anti-LXR $\alpha$ (ab3585), anti-PSD95 (ab18258), anti-GABA ${ }_{\mathrm{A}} \mathrm{R}-\alpha 2$ (ab72445), anti-GABA ${ }_{\mathrm{A}} \mathrm{R}-\gamma 2$ (ab186396), anti-GluR1 (ab31232), anti-CaMKII $\alpha$ (ab22609), anti-GAD67 (ab26116), anti-Ser845-phosphoGluR1 (ab76321), and anti-Ser831-phospho-GluR1 (ab109464) antibodies were purchased from Abcam (Cambridge, UK, USA). Anti-NR2A (MAB5216) and antiNR2B (MAB5780) antibodies were obtained from Millipore (Bedford, MA, USA), and anti- $\beta$-actin (A5316) antibody was 
obtained from Sigma-Aldrich (St. Louis, MO, USA). All secondary antibodies conjugated with horseradish peroxidase (HRP) were purchased from Santa Cruz (CA, USA), Alexa Fluro 488 and 594 goat IgG were purchased from Molecular Probes (Eugene, OR, USA). BCA Kit, M-PER Protein Extraction Buffer and enhanced chemiluminescent solution (ECL) were obtained from Pierce (Rockford, IL, USA). PVDF membrane was purchased from Roche (Mannheim, Germany). GW3965 (purity > 98\%) was purchased from Selleckchem (Shanghai, China) and dissolved in sterile $0.1 \%$ DMSO to desired concentrations before use. 2,4Dinitrofluorobenzene (DNFB, 42085), glutamate (49621), and GABA (43811) standards were obtained from SigmaAldrich. All chemicals were obtained from Sigma unless otherwise stated.

\section{Acute Stress Model and Drug Treatment}

6- to 8-week-old C57BL/6 male mice (bodyweight 20-25 g) were obtained from the Experimental Animal Center of Fourth Military Medical University (certificate No. 201000082, Grade II). All experimental procedures were approved by the Fourth Military Medical University Animal Care and Use Committee. Every effort was made to minimize the number of animals used and their suffering. Mice were individually housed in standard plastic cages with food and water available ad libitum. The room was maintained at controlled temperature $\left(22 \pm 24^{\circ} \mathrm{C}\right)$ with humidity (50-60\%), and a reversed 12:12-h light/dark cycle. Before testing, the animals need to adapt to laboratory conditions for at least 1 week. Forced swimming (FS) stressor is extensively used to induce anxious behaviors [19]. In the experiment, mice were randomly divided into several groups: control group (no stress), stressed group with or without GW treatment. The stressed mice were forced to swim for $30 \mathrm{~min}$ in an open cylindrical container $(10 \mathrm{~cm}$ in diameter and $30 \mathrm{~cm}$ in height) filled with water $\left(22 \pm 1{ }^{\circ} \mathrm{C}\right)$ to $20 \mathrm{~cm}$ in height for 2 days consecutively. Mice were removed, wiped dry from the water after FS and placed into cages with food and water ad libitum. The mice received $\mathrm{GW}(10 \mathrm{mg} / \mathrm{kg}$ ) or vehicle (saline, $10 \mathrm{ml} / \mathrm{kg}$ ) by intraperitoneal (i.p.) injection once daily for 2 days consecutively before first FS. Mice in the control group were placed in comfortable cages during this period.

\section{Elevated Plus Maze}

Anxiety-related behavior was measured using elevated plus maze (EPM) as described previously [4]. The EPM test was conducted after the last FS. The equipment contains two open arms $(25 \mathrm{~cm} \times 8 \mathrm{~cm} \times 0.5 \mathrm{~cm})$ and two closed arms $(25 \mathrm{~cm} \times$ $8 \mathrm{~cm} \times 12 \mathrm{~cm})$, with a common central platform $(8 \mathrm{~cm} \times$ $8 \mathrm{~cm})$. The apparatus was elevated to a height of $50 \mathrm{~cm}$ above the floor. In order to avoid environmental factors, all mice were allowed to habituate to the testing room for $2 \mathrm{~h}$ before the behavioral test. Then the mice were tested on the central platform, facing an open arm, and allowed to move freely for $5 \mathrm{~min}$. The motor activities were recorded by camera and analyzed with a video-tracking system. The anxiety of animals was caused by the conflict behavior for exploring novel environment and an inborn fear of high hung open arm. Herein, the number of arm entries and the proportion of time spent in the open arms were calculated as the evaluation index of anxiety.

\section{Open Field Test}

As described in previous reports, the open field test (OFT) was conducted in an apparatus consisted of a $30 \mathrm{~cm} \times 30 \mathrm{~cm} \times$ $30 \mathrm{~cm}$ square box (JL Behv-LAM, Shanghai, China). Briefly, mice were tested in the center area after adaptation to the environment for $2 \mathrm{~min}$. The mice were allowed to move freely and motor activities were videotaped using a camera fixed above the box during a 15 min-session. The "center" field is defined as the central $15 \mathrm{~cm} \times 15 \mathrm{~cm}$ area of the open field, one-fourth of the total area. The time in the central area and distance traveled were analyzed by using a motion tracking system (Med Associates, St. Albans, VT).

\section{Immunofluorescence Staining}

Mice were anesthetized with sodium pentobarbital $(40 \mathrm{mg} / \mathrm{kg}$, i.p.) at the end of the last behavior test, and then were perfused intracardially with saline followed by $4 \%$ paraformaldehyde (PFA) in 0.1 M phosphate buffer solution (PBS, pH 7.4). After dehydration, floating coronal sections containing amygdala $(30 \mu \mathrm{m})$ were collected in PBS using CM3050S freezing microtome (Leica, Germany). The cryosections containing BLA were washed with $0.1 \%$ Triton X-100 in PBS for 30 min and blocked in $10 \%$ goat serum for $1 \mathrm{~h}$ at room temperature. The slices were incubated with primary antibodies including anti$\operatorname{LXR} \alpha$ (1:200), anti-LXR $\beta$ (1:200), anti-CaMKII $\alpha$ (1:200), or anti-GAD67 (1:200) overnight at $4{ }^{\circ} \mathrm{C}$, followed by Alexa Fluor secondary antibody incubation. Nuclei were counterstained with Hoechst 33258. Fluorescent signals were photographed and analyzed using confocal microscopy (Olympus, Japan).

\section{Determination of Glutamate and GABA Levels in the Amygdala}

The mice were executed after the behavior test and the fresh brains were immediately obtained. The basolateral amygdala tissue samples were isolated under a dissecting microscope, weighted and homogenized in 9 vol. of methanol/water $(50: 50, \mathrm{v} / \mathrm{v})$. The homogenates were centrifuged at $4000 \times \mathrm{g}$, $4{ }^{\circ} \mathrm{C}$ for $15 \mathrm{~min}$ and the clean supernatant was stored at $20{ }^{\circ} \mathrm{C}$ until derivatization. Derivatization was performed by 


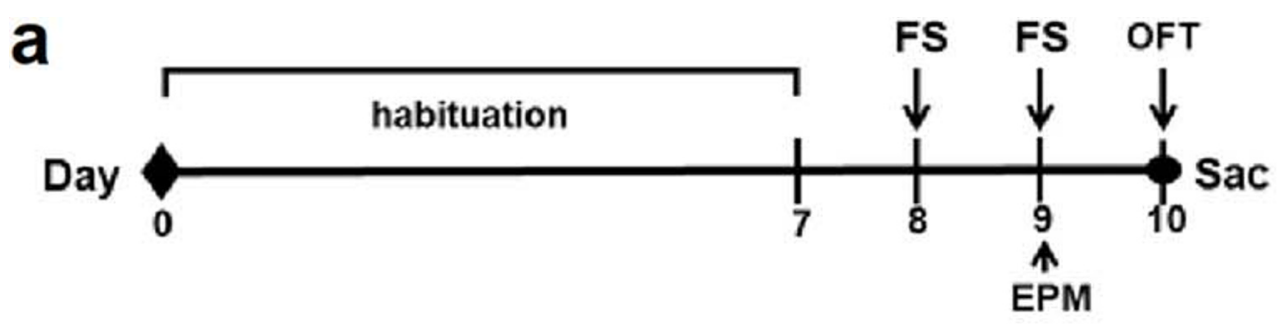

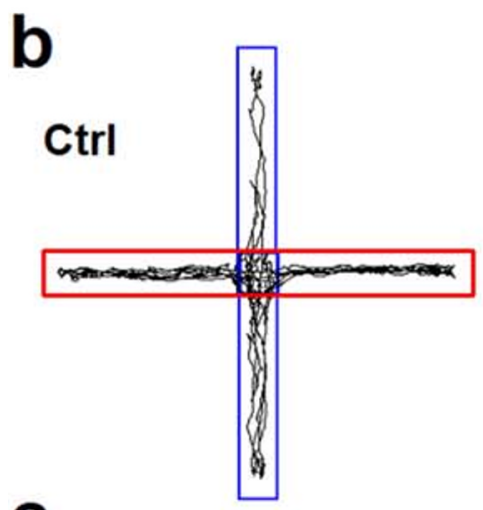

C
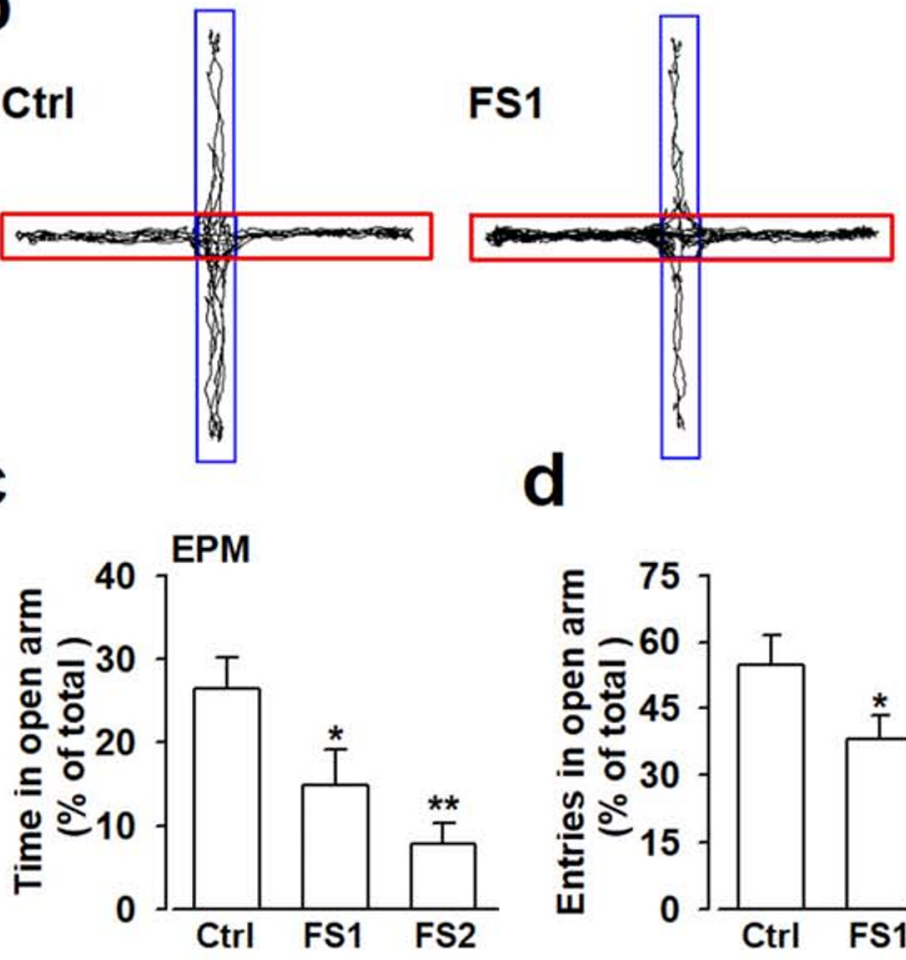
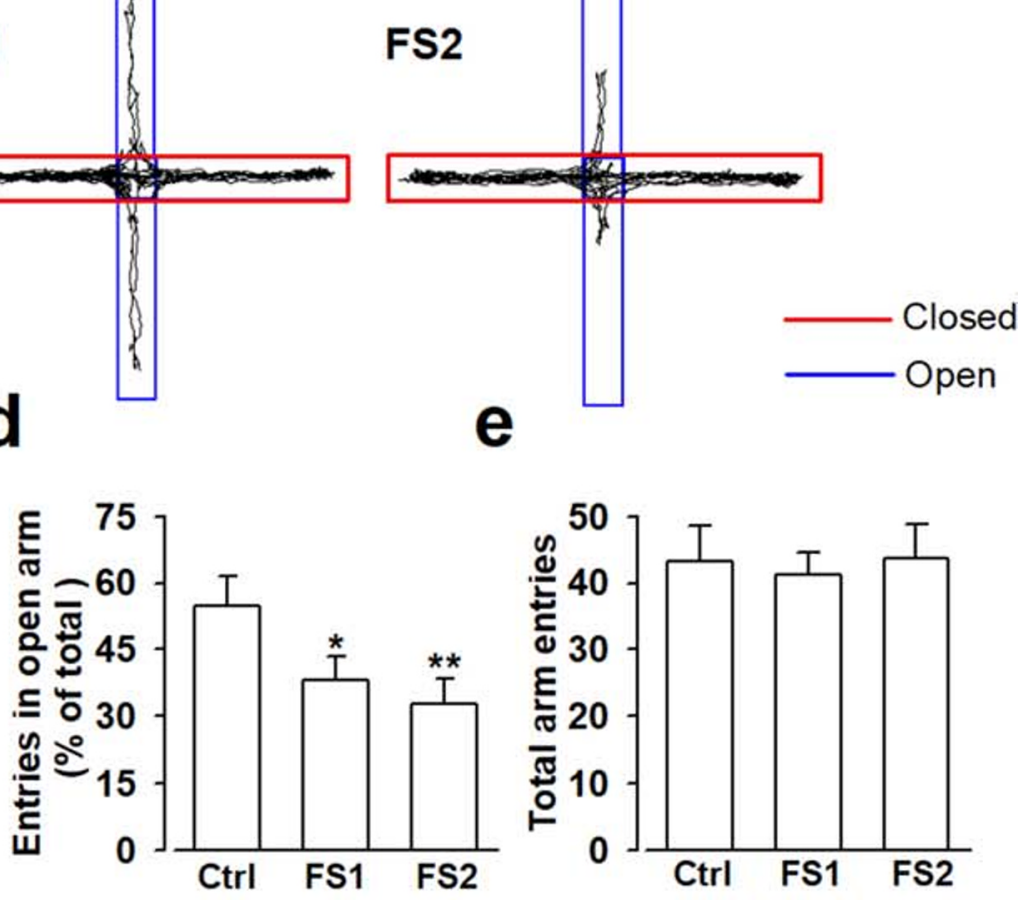

e

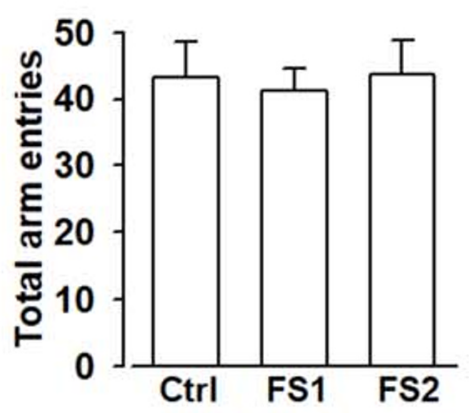

f
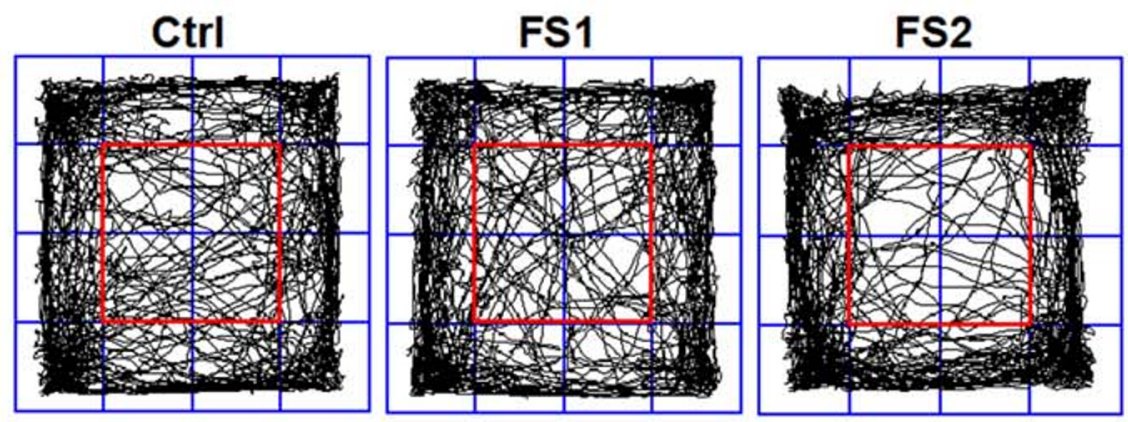

g

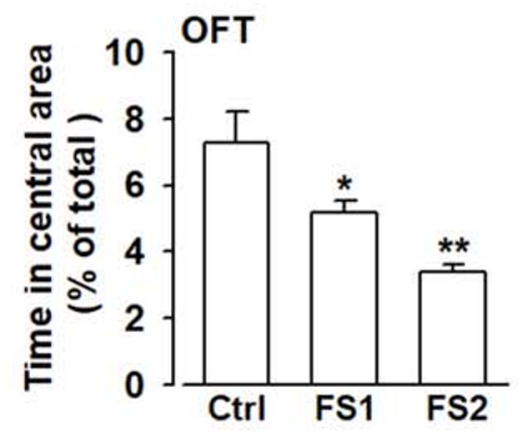

h

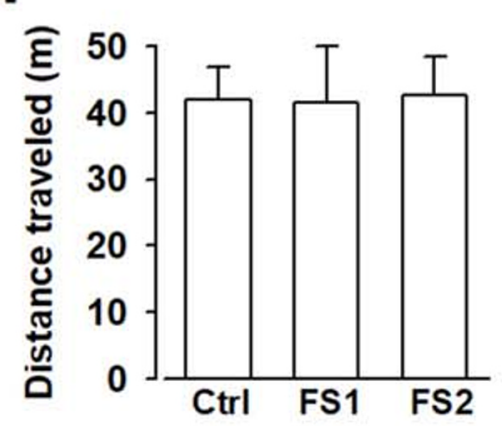


Fig. 1 Effect of forced swimming on mice behavioral performance. Mice were stressed by forced swimming (FS) once (one swim of 30 min, FS1) or twice (one 30 min-swim per day, for 2 days, FS2), then anxiety-like behaviors were determined by elevated plus maze test (EPM) and open field test (OFT). (a) Schematic illustration of the experiment. (b) The track traces of mice in the EPM test. (c) The time spent in the open arms, (d) the entries in the open arms, and (e) the total arm entries in EPM test from each group. (f) The track traces of mice in OFT test. (g) The time spent in the central area and (h) the total distance traveled in the OFT test from each group. Acute stress-induced by FS resulted in anxiety-like behaviors characterized as less time spent in the open arms (c) and the central area (g), less entries to the open arms (d) compared with control mice. Each value represented the mean \pm SEM of three independent experiments ( $n=6$ experiments, ${ }^{*} p<0.05, * * p<0.01$, vs control group)

mixing standards or samples with acetonitrile DNFB $(0.5 \%)$ for $1 \mathrm{~h}$ at $60^{\circ} \mathrm{C}$. Then $20 \mu \mathrm{L}$ mixture was injected into the HPLC system for analysis [20]. The levels of Glu and GABA were determined using a Waters 2695 liquid chromate graph (Waters, Milford, CT, USA), Hypersil ODS C18 column (250 by $4.6 \mathrm{~mm}$; particle size, $5 \mu \mathrm{m}$ ), coupled with a Waters 2996 UV/VIS detector. The mobile phase consisted of $8 \%$ methyl cyanides, $8 \% \mathrm{ddH}_{2} \mathrm{O}$, and $84 \% \mathrm{NaH}_{2} \mathrm{PO}_{4}(40 \mathrm{mM}, \mathrm{pH} 8.0)$ at a flow rate of $1.0 \mathrm{ml} / \mathrm{min}$. Chromatograms of Glu and GABA standards yielded peaks at $7.968 \mathrm{~min}$ and $29.896 \mathrm{~min}$ respectively at an absorbance of $360 \mathrm{~nm}$. The concentration was calculated by LC solution software (Waters, Milford, CT, USA) based on standard samples.

\section{Stereotactic Microinjection of Lentivirus-Encoding shRNAs}

To knock down the endogenous LXR $\beta$ expression, shRNAcoding plasmids against LXR $\beta$ (NM_009473.3) were designed according to the validated shRNA sequences [21, 22]. Lentivirus (pGLV-U6-GFP)-encoding shRNAs for LXR $\beta$ was prepared by GenePharma (Shanghai, China). The shRNA sequence for LXR $\beta$ was 5'-GGAT TCAGAAGCAGCAACAT-3'. Mice were anesthetized with a mixture of ketamine $(100 \mathrm{mg} / \mathrm{kg}$, i.p. $)$ and xylazine $(20 \mathrm{mg} / \mathrm{kg}$, i.p.) and were mounted on a stereotaxic apparatus (RWD68001, Shenzhen Ruiwode Life Science, China). Briefly, two small holes were carefully drilled on the skull bilaterally, and an attenuated glass electrode (approximately $10 \mu \mathrm{m}$ in diameter) was implanted bilaterally into the amygdala $(-1.45 \mathrm{~mm}$ anteroposterior, $\pm 2.5 \mathrm{~mm}$ lateral to the midline, and $-4.3 \mathrm{~mm}$ dorsoventral). The mice received $2 \mu \mathrm{l}$ $\operatorname{shLXR} \beta\left(1 \times 10^{9} \mathrm{gc} / \mathrm{ml}\right)$ bilaterally at $0.25 \mu \mathrm{l} / \mathrm{min}$ driven by an infusion pump (Harvard Apparatus, MA). An additional 5 min was allowed for virus diffusion, and negative shRNA for LXRs (shNC) served as a lentivirus infection control. The stress-induced anxiety model was set up 14 days after shRNA infection, and mice were treated as before.

\section{Western Blot Analysis}

Samples from mice amygdala were collected at the end of behavior tests. Total proteins were lysed by M-PER Protein Extraction Buffer containing a proteinase inhibitor mixture and PMSF $(10 \mu \mathrm{M})$ according to the manufacturer's instructions. Protein concentrations were determined using a BCA Kit. Equal amounts of protein aliquots were used to check the expression levels of target proteins using anti-LXR $\beta$ (1:500), anti-LXR $\alpha$ (1:500), anti-NR2A (1:1000), anti-NR2B (1:1000), anti-GluR1 (1:1000), anti-Ser845-phospho-GluR1 (1:1000), anti-Ser831-phospho-GluR1 (1:1000), anti-PSD95 (1:1000), anti-GABA $A_{A} R-\alpha 2(1: 1000)$ and anti-GABA $A_{A} R-\gamma 2$ (1:1000) through $10 \%$ SDS-PAGE gel electrophoresis, and $\beta$ actin served as a loading control. After incubation with the appropriate HRP-coupled secondary antibody, the proteins were visualized using ECL. The density of immunoblots was conducted using ChemiDoc XRS (Bio-Rad, Hercules) and quantified using Quantity One version 4.1.0 (Bio-Rad).

\section{Whole-Cell Patch Clamp Recording}

Coronal brain slices $(300 \mu \mathrm{m})$ containing BLA were prepared as described previously [4]. Slices were transferred to a recovery chamber with artificial cerebrospinal fluid (ACSF) containing the followings (in $\mathrm{mM}$ ): $\mathrm{NaCl} 125, \mathrm{KCl} 2.5, \mathrm{CaCl}_{2}$ 2.0, $\mathrm{MgCl}_{2}$ 1.0, $\mathrm{NaHCO}_{3} 26.0, \mathrm{NaH}_{2} \mathrm{PO}_{4}$ 1.25, glucose 25.0 , bubbled with a mixture of $95 \% \mathrm{O}_{2}$ and $5 \% \mathrm{CO}_{2}$ for at least $1 \mathrm{~h}$ at room temperature. Whole-cell voltage clamp recordings were obtained from BLA neurons performed with an Axopatch 200B amplifier (Axon Instruments, Union City, CA, USA). Patch electrodes (3-7 M $\Omega$ ) were pulled from thin-wall glass tubing (GD-1.5, Narishige, Japan) and filled with an internal solution that contained $(\mathrm{mM})$ : Cs methanesulphonate $130.0 ; \mathrm{NaCl} 8.0 ; \mathrm{MgCl}_{2} 2$; K-EGTA 10.0; Na-HEPES 10.0; K-ATP 4.0; pH 7.4. Miniature excitatory postsynaptic currents (mEPSCs) were recorded under voltage clamp at $-70 \mathrm{mV}$ in the presence of tetrodotoxin (TTX, $0.001 \mathrm{mM})$, D-AP5 $(0.05 \mathrm{mM})$ and picrotoxin (PTX, $0.1 \mathrm{mM})$. For miniature inhibitory postsynaptic currents (mIPSCs) recordings, the PTX in ACSF was replaced with CNQX $(0.02 \mathrm{mM})$ and cells were held at $0 \mathrm{mV}$. Miniature synaptic currents were analyzed using Mini Analysis software with a threshold of $\pm 5 \mathrm{pA}$ for the event detection. Statistical differences between amplitude distributions of miniature synaptic currents before and after drug treatments were assessed by the Kolmogorov-Smirnov test.

\section{Statistical Analysis}

Results were analyzed by SPSS 19.0 and expressed as mean \pm SEM. Appropriate statistical approaches including one ANOVA were used followed by a least significant 


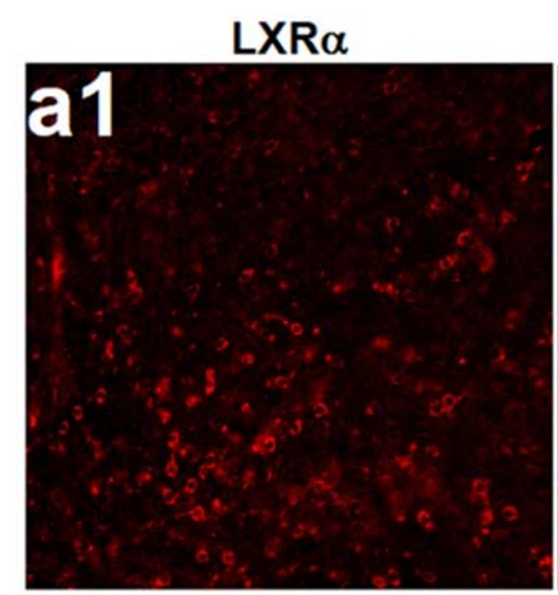

LXRß
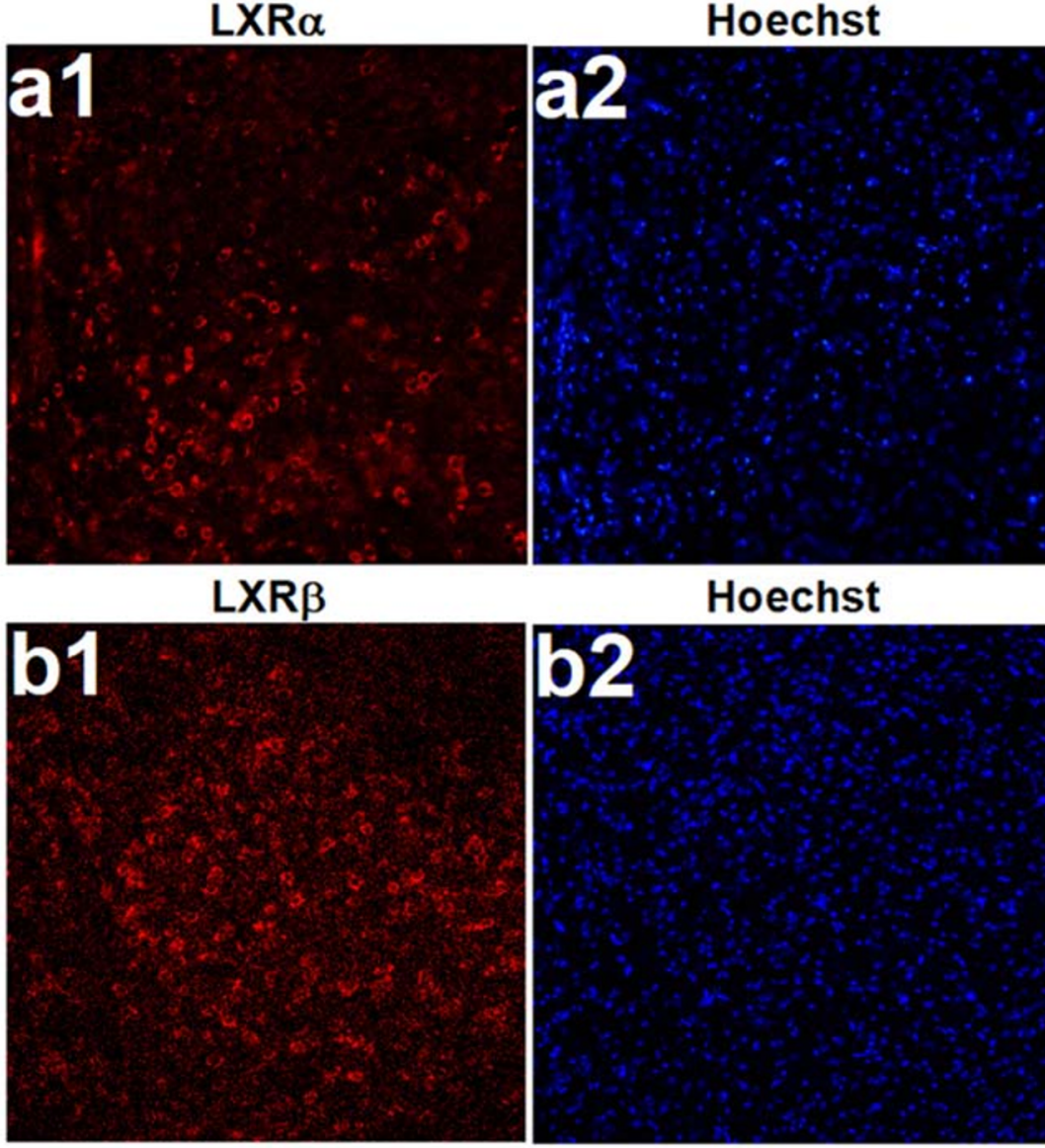

Hoechst
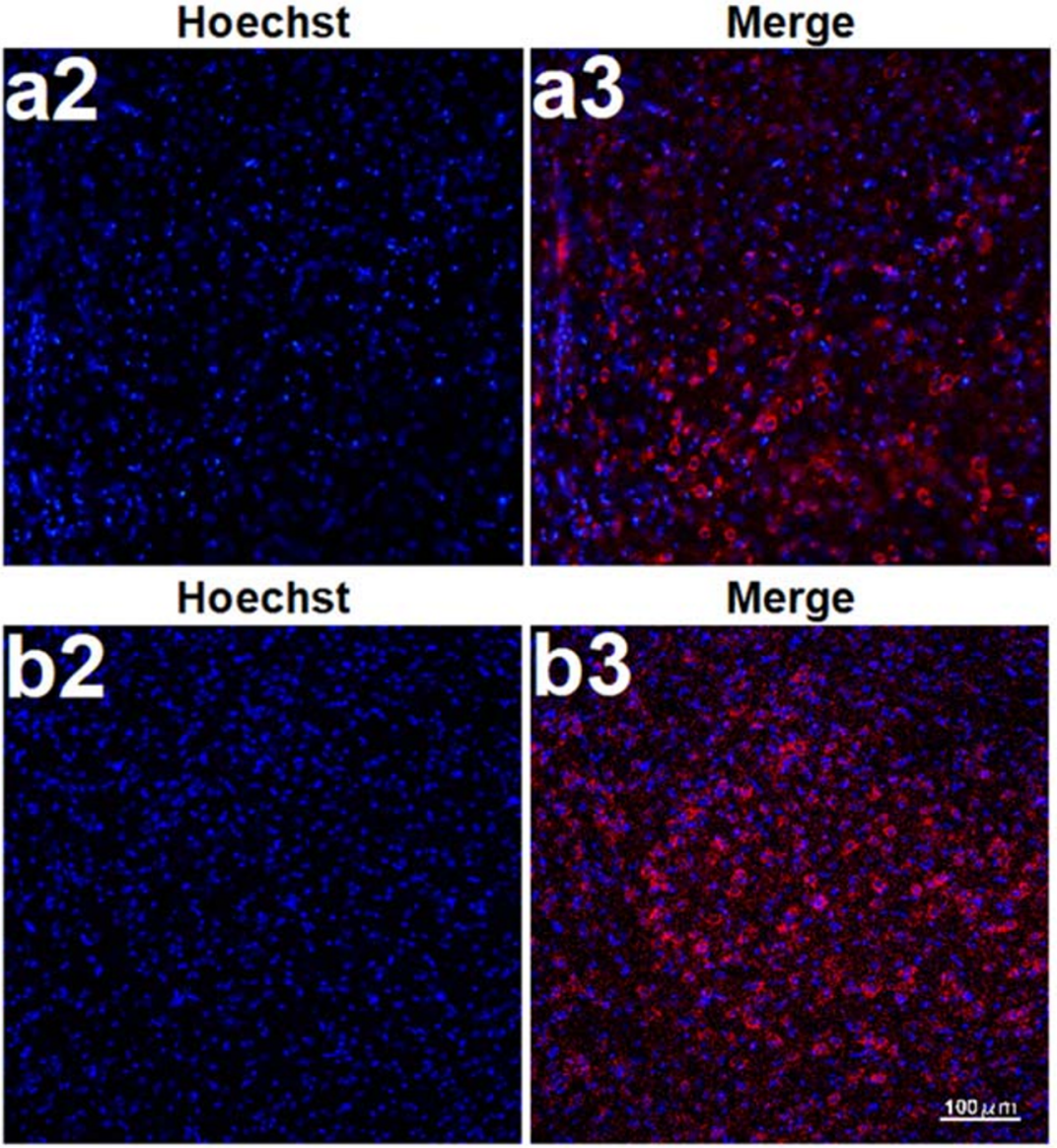

Merge

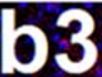

$100 \mathrm{um}$
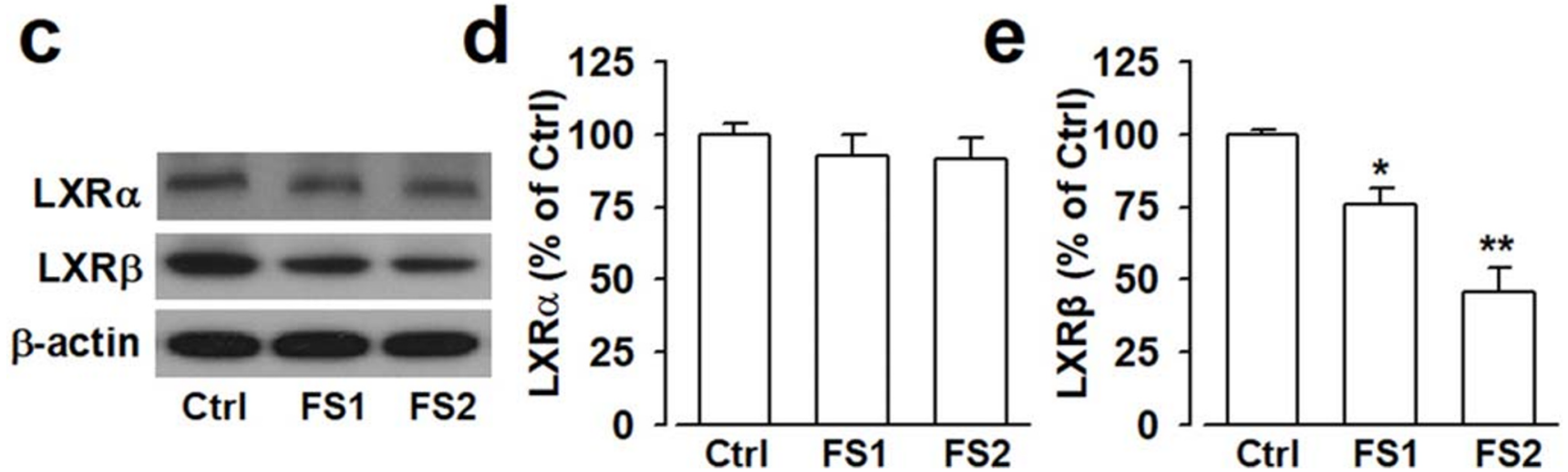

Fig. 2 Forced swimming led to the reduction of $L X R \beta$ expression in theamygdala of mice. Mice were stressed with forced swimming (FS) once (one swim for $30 \mathrm{~min}, \mathrm{FS} 1$ ) or twice (one $30 \mathrm{~min}$-swim per day, for 2 days), and brain slices containing amygdala were harvested to determine the expression changes of LXRs. Representative examples of immunostaining showed the expression of (a) $\operatorname{LXR} \alpha$ and (b) LXR $\beta$ in the amygdala from control mice. (c) Western blot analysis showed no

difference (LSD) test. The distributions of current amplitude and frequency were examined by KolmogorovSmirnov test. The $p$ value of less than $0.05(p<0.05)$ was considered statistically significant. All statistical analyses were conducted using SigmaPlot 2001 (Systat Software, Point Richmond, CA, USA). changes of LXR $\alpha$ expression and reduced LXR $\beta$ expression in the amygdala after FS2 stress compared with the control group, and $\beta$-actin served as internal control. Quantitative data for the expression of (d) $\operatorname{LXR} \alpha$ and (e) LXR $\beta$ were showed. Each value represented the mean \pm SEM of three independent experiments $(n=6$ experiments, $* p<0.05$, $* * p<0.01$, vs control group)

\section{Results}

\section{Acute Stress-Induced Mice Anxiety-Like Behaviors}

Stress exposure, especially psychological stress including forced swimming, daily restraint, and chronic social defeat 
lead to the anxiety-like behaviors [23] or typically facilitate anxiety [24]. In the experiment, mice were divided into forced swimming once (one swim of $30 \mathrm{~min}, \mathrm{FS} 1$ ) group, twice (one 30 min-swim per day, for 2 days, FS2) group, and control group. On the first day, FS2 were forced to swim, while FS1 and control did not do the treatment. The next day FS1 and FS2 were forced to swim, and the control group did not do the treatment. Then the behavior tests were conducted after last forced swimming. In order to determine whether FS induced anxiety disorder, animal anxiety-like behaviors were determined by EPM and OFT. The time spent in the open arms, the total number of arm entries in EPM, and the time spent in the central area in OFT were used as an index of anxiety-like behaviors to confirm the effects of repeated stress procedure. Compared with the control (Ctrl) group, mice that were FS-stressed once (one forced swim for $30 \mathrm{~min}, \mathrm{FS} 1$ ) or twice (one $30 \mathrm{~min}$ swim per day, for 2 days, FS2) spent less time in the open arms (Fig. 1b, c), and avoided to enter the open arm (Fig. 1b, d) in EPM. There were no significant changes in the total arm entries between each group (Fig. 1b, e). Behavioral differences among groups were also determined using OFT, and we found that the time spent in the central area in the OFT prominently decreased in the FS2 mice compared with the control group (Fig. 1f, g). However, the total distance traveled did not change in each group (Fig. 1f, h). This observation indicated the acute stress by FS induced mice anxiety-like behaviors.

\section{Acute Stress Led to the Reduction of LXR $\beta$ Expression Level in BLA}

LXRs have been implicated in regulating cellular immunity, homeostasis, and neuroinflammation in the CNS. However, the role of LXRs in acute stress-induced anxiety is rarely reported. Immunofluorescence staining showed that LXR $\beta$ was widely expressed in amygdala, a critical region responsible for mood processing, whereas the expression of $\operatorname{LXR} \alpha$ was limited in the amygdala (Fig. 2a, b). To determine whether LXR signaling was required for anxiety development, Western blot analysis was used to check the expression changes of LXRs in mice anxiety model. The results showed that LXR $\alpha$ had low basal expression in the amygdala of naive mice and was not altered after FS (Fig. 2c, d). However, LXR $\beta$ was relatively strongly expressed in the amygdala from
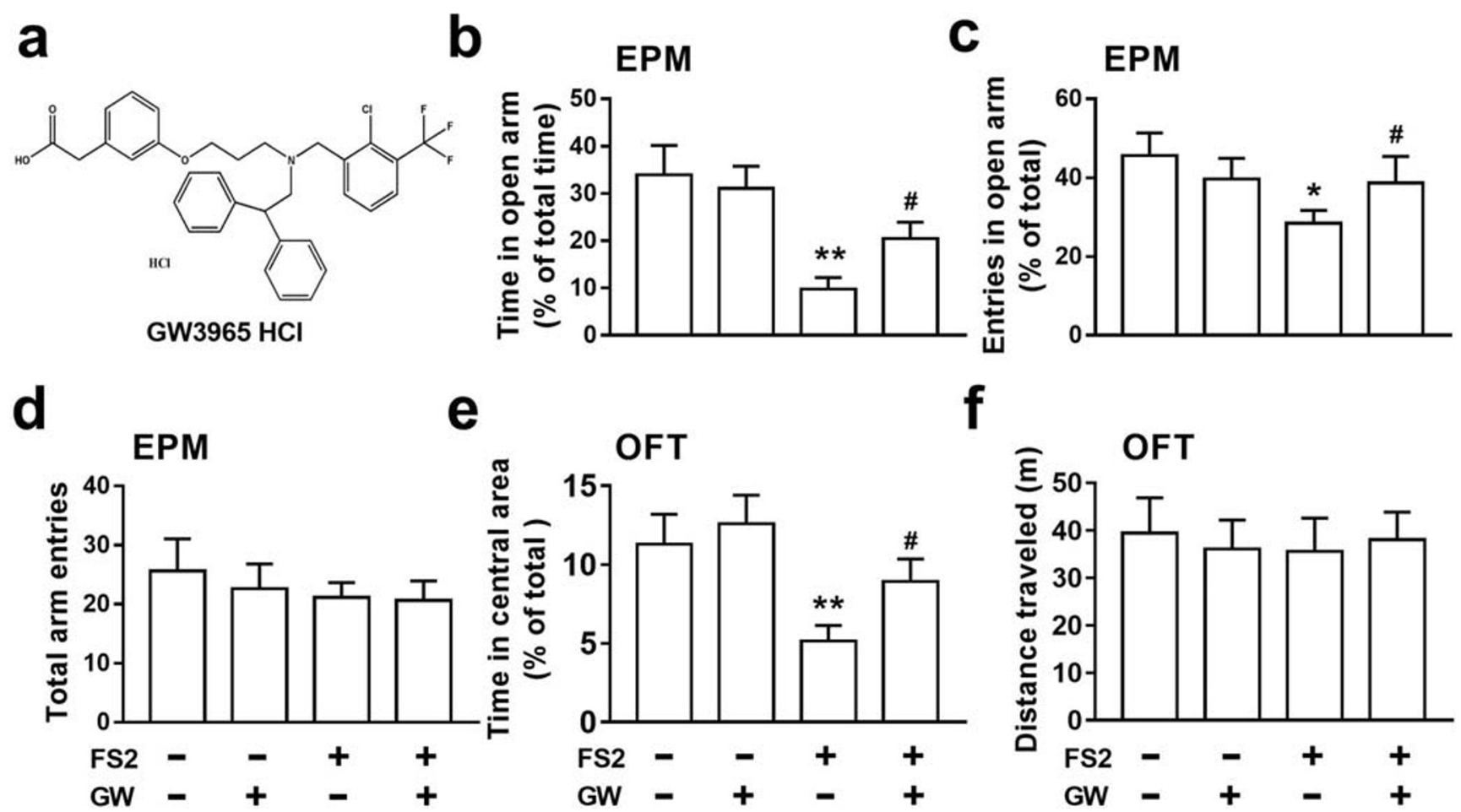

Fig. 3 LXRs agonist GW3965 reversed FS2-elicited anxiety-like behaviors. GW3965 (GW, $10 \mathrm{mg} / \mathrm{kg}$ ) was administered by intraperitoneal (i.p.) injection once a day before acute stress-induced by forced swimming twice (one 30 min-swim per day, for 2 days, FS2), then the effects of GW on anxiety-like behaviors were determined by elevated plus maze test (EPM) and open field test (OFT). (a) The chemical structure of GW3965. (b) The time spent in the open arms, (c) the entries in the open arms, and

(d) the total arm entries in the EPM test from each group. (e) The time spent in the central area and (f) the total distance traveled in OFT. GW administration alleviated FS2-stressed mice anxiety-like behaviors but had no effect on control mice. Each value represented the mean \pm SEM of three independent experiments $(n=6$ experiments, $* * p<0.01$, vs control group; ${ }^{*} p<0.05$, vs FS2-stressed group) 
healthy mice, and FS2 resulted in a significant reduction of LXR $\beta$ expression in the amygdala (Fig. 2c, e). The above results indicated that FS2 stress successfully induced mice anxiety-like behaviors, linking LXR $\beta$ deficit with the anxiety-related behaviors.

\section{Activation of LXRs Alleviated Anxiety-Related Behaviors Induced by Acute Stress}

LXR $\beta$ expression in BLA decreased in the FS2-stressed mice (Fig. $2 \mathrm{c}$, e), raising the possibility that LXR $\beta$ influenced the development of anxiety. We hypothesized that the activation of LXR $\beta$ may exert anxiolytic effects in stressed mice. Given the lack of selective agonist for LXR isoforms, the FS2stressed mice were administrated with GW (Fig. 3a), an $\mathrm{LXR} \alpha / \beta$ dual agonist, to evaluate the anxiolytic effects after LXRs activation. We found that GW obviously alleviated anxiety-related behaviors induced by FS2 acute stress examined by EPM and OFT as before. Compared with the FS2 group, FS2-stressed mice treated with GW (FS2+GW) featured a strong anxiolytic-like response as shown by more time spent in open arms (Fig. 3b) along with more entries in these arms (Fig. 3c) in EPM. Meanwhile, GW-treated mice also exhibited a higher time percent in the central area of OFT (Fig. 3e) compared with the FS2-stressed group. However, there were no statistical differences in the total arm entries in

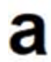

a

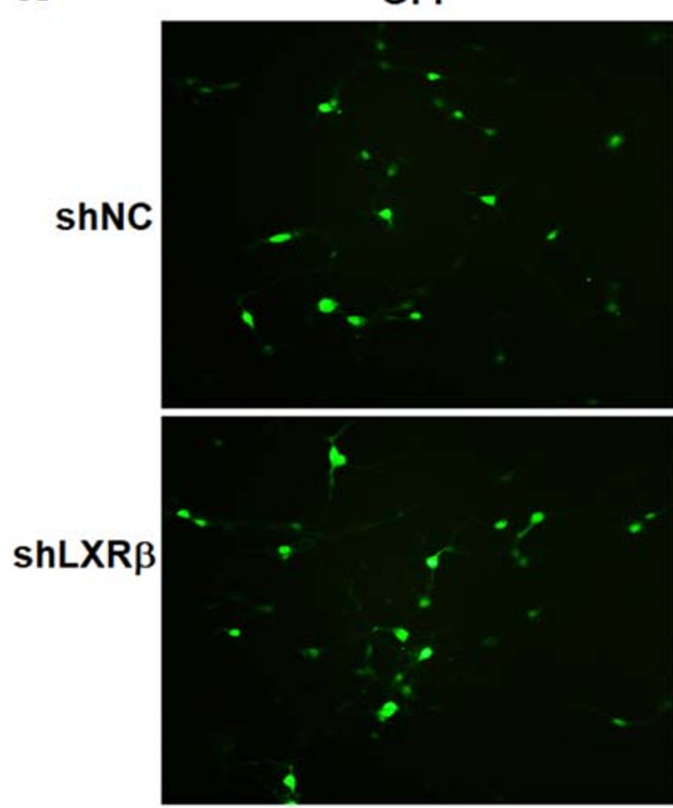

C

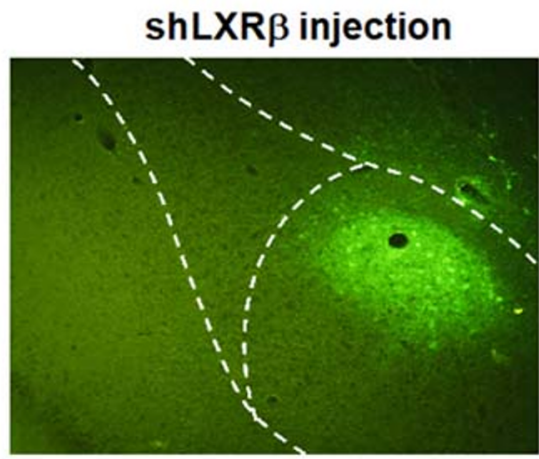

Fig. 4 Knockdown of LXR $\beta$ expression by shRNA in cultured neurons and amygdala. (a) Cultured neurons were infected with LXR $\beta$-shRNA $(\operatorname{shLXR} \beta)$ or negative shRNA $(\operatorname{shNC})$ for $72 \mathrm{~h}$, and the efficiency of infection was observed as green fluorescence (GFP) by fluorescence microscope after infection with shRNA lentivirus $(\times 20)$, and corresponding bright field showed all the cultured neurons after infection. (b) Representative Western blots of LXR $\beta$ expression level of neurons that infected with $\operatorname{shLXR} \beta$ or shNC for $72 \mathrm{~h}, \beta$-actin served as internal

\section{Bright field}
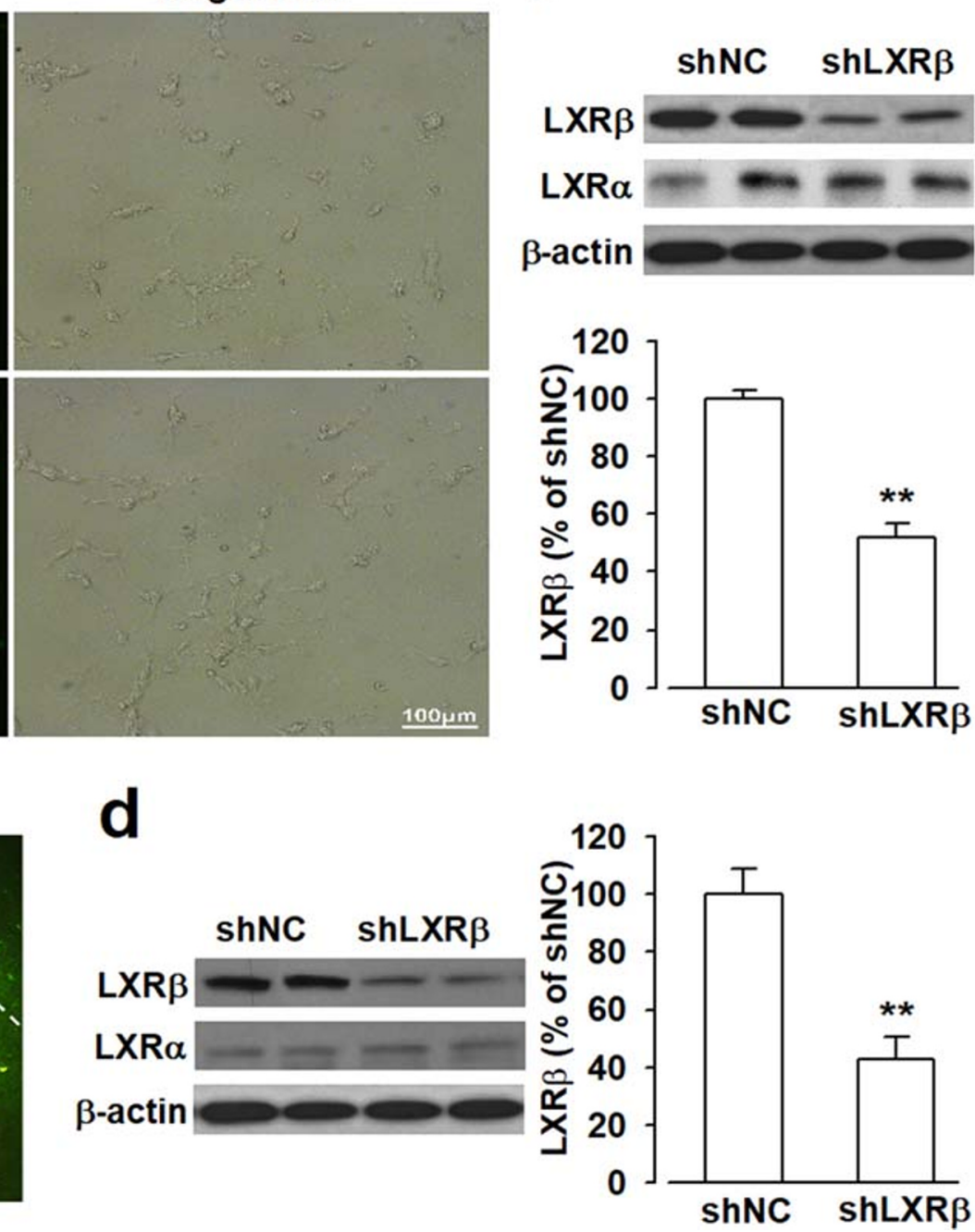

control. shLXR $\beta$ decreased the expression level of LXR $\beta$ in cultured neurons. (c) Green fluorescence represented cells in the amygdala that were infected by shRNA lentivirus for 14 days $(\times 10)$. (d) Representative Western blots of LXR $\beta$ expression level in amygdala infected with $\operatorname{shLXR} \beta$ or shNC for 14 days, $\beta$-actin served as internal control. $\operatorname{shLXR} \beta$ decreased the expression level of LXR $\beta$ in the amygdala. Error bars represented SEM. $n=6, * * p<0.01$, versus shNC-injected group 
EPM (Fig. 3d) and the total distance traveled in OFT (Fig. 3f) between each group. Collectively, the result indicated that LXR activation by GW alleviated mice anxiety-like behaviors after FS2 stress, and GW treatment did not affect the behaviors in control mice (Fig. 3).

\section{GW3965 Ameliorated Anxiety-Like Behaviors Through LXRß Isoform}

Given the lack of selective agonists for $\operatorname{LXR} \alpha$ or LXR $\beta$ isoform, we applied specific shRNA-mediated knockdown of LXRs in the amygdala to check the roles of LXR $\beta$ in GWmediated anxiolytic effects. The cultured neurons expressed green fluorescent protein (GFP) after transfection with LXR $\beta$ shRNA $(\operatorname{shLXR} \beta)$ or negative control shRNA (shNC). $88.41 \% \pm 5.36 \%$ neurons were GFP positive after shRNA infection for $72 \mathrm{~h}$ (Fig. 4a), indicating shRNA infected cultured neurons successfully. Western blot analysis showed $\operatorname{shLXR} \beta$ induced a knockdown of LXR $\beta$ expression to $52.07 \% \pm$ $4.46 \%$ of shNC in cultured neurons (Fig. 4b). To test the knockdown effect of $\operatorname{shLXR} \beta$ in the brain, $2 \mu 1$
shLXR $\beta$ lentivirus $\left(1 \times 10^{9} \mathrm{gc} / \mathrm{ml}\right)$ were locally microinjected into bilateral BLA of the amygdala. Brain slices were harvested for fluorescence observation after infection for 14 days and lentivirus for $\operatorname{shLXR} \beta$ or shNC successfully infected cells in BLA (Fig. 4c). Protein samples from the amygdala were collected to determine the expression level of LXR $\beta$ by Western blot, and the results showed that $\operatorname{shLXR} \beta$ resulted in a reduction of LXR $\beta$ protein expression to $42.76 \% \pm$ $7.52 \%$ of shNC (Fig. 4d). Therefore, $\operatorname{shLXR} \beta$ and shNC could be used to evaluate the exact mechanisms of LXR $\beta$ isoform involved in the further study.

All the data showed that lentiviral $\operatorname{shLXR} \beta$ effectively knocked down LXR $\beta$ expression both in vitro and in vivo, then the roles of LXR $\beta$ in GW-mediated anxiolytic effects were further investigated. The anxiolytic effects mediated by GW were measured using EPM and OFT after $2 \mu \mathrm{l} \mathrm{shLXR} \beta$ lentivirus were microinjected into the BLA for 14 days. Behavior test results showed that shNC infection did not alter mouse performance compared to normal control mice (data not shown). Infection of shNC lentivirus did not affect the
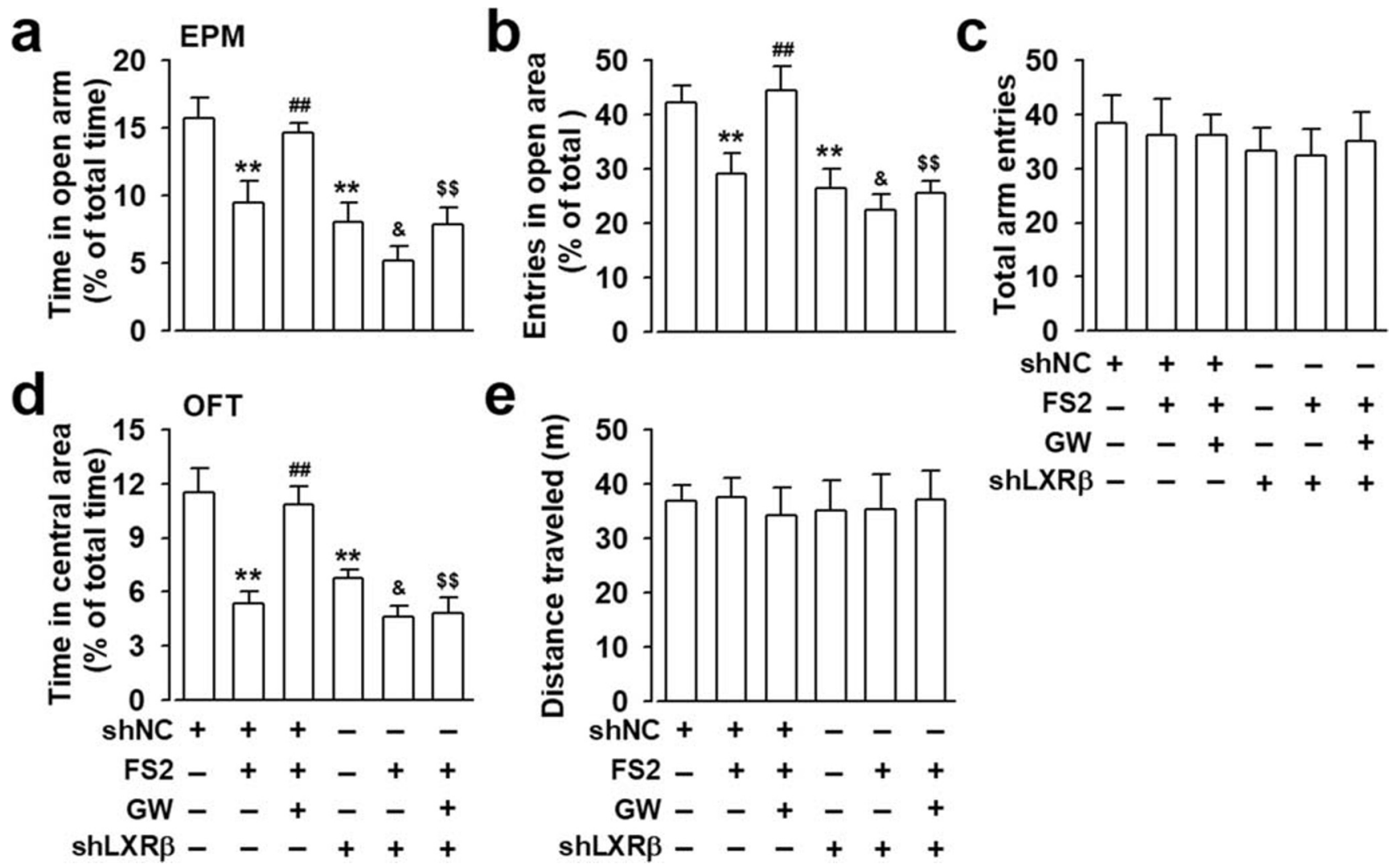

Fig. 5 Knockdown of LXR $\beta$ expression in the amygdala by $\operatorname{shLXR} \beta$ blocked GW3965-mediated anxiolytic effects in FS2-stressed mice. Mice were infected with LXR $\beta$-shRNA (shLXR $\beta$ ) or negative shRNA (shNC) in the amygdala for 14 days, followed by forced swimming twice (one 30 min-swim per day, for 2 days, FS2) with or without GW3965 (GW, $10 \mathrm{mg} / \mathrm{kg}$, i.p.) administration, then the effects of $\mathrm{GW}$ on anxiety-like behaviors were determined by elevated plus maze test (EPM) and open field test (OFT). (a) The time spent in the open arms, (b) the entries in the open arms, and (c) the total arm entries in the EPM test from each group. (d) The time spent in the central area and (e) the total distance traveled in OFT. Each value represented the mean \pm SEM of three independent experiments $\left(n=6,{ }^{*} p<0.01, v s\right.$ shNC-injected group; ${ }^{\# \#} p<0.01, v s$ shNC+FS2 group; ${ }^{\&} p<0.05$, vs shLXR $\beta$ group; ${ }^{\$ \$} p<0.01$, vs shNC+ FS2+GW group) 
a

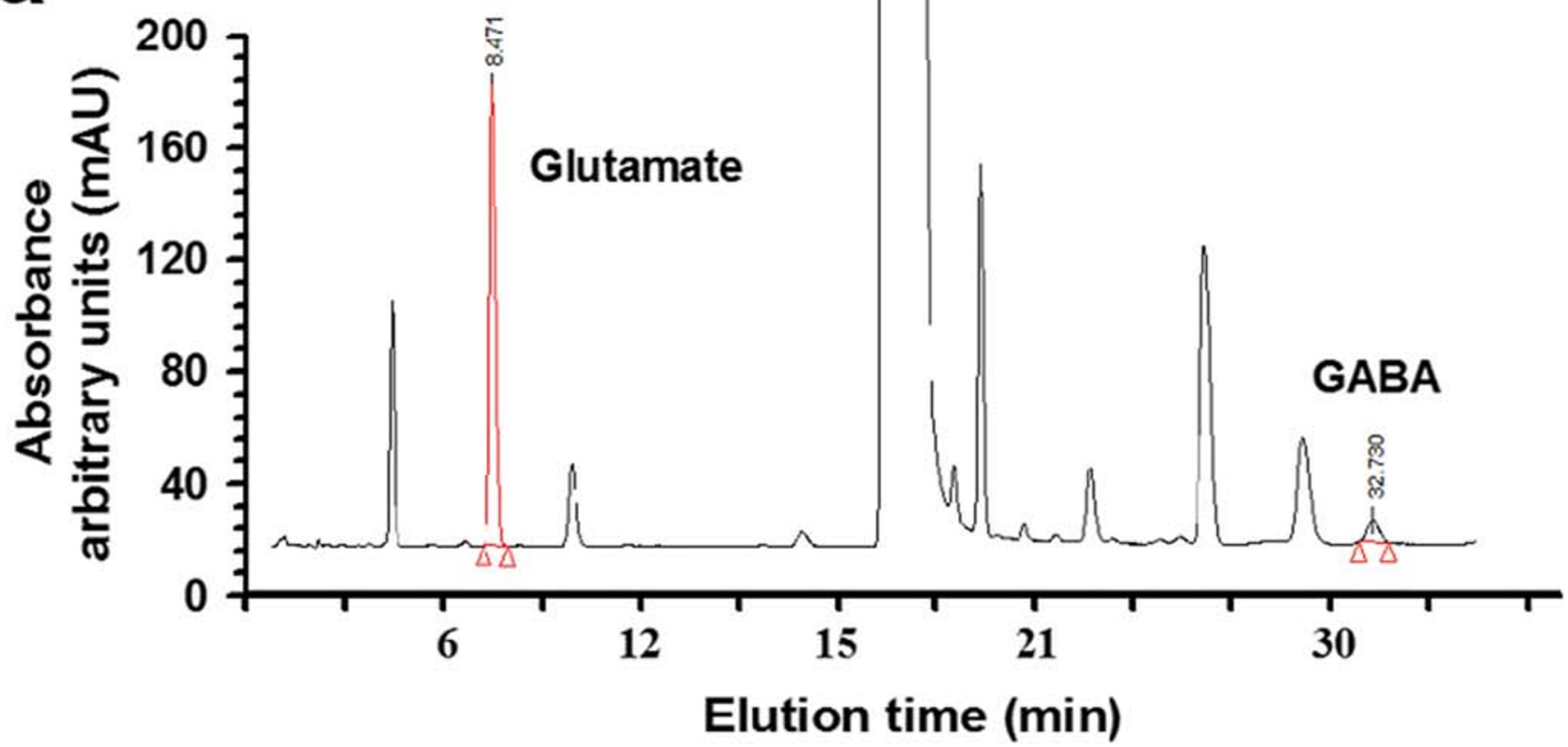

b
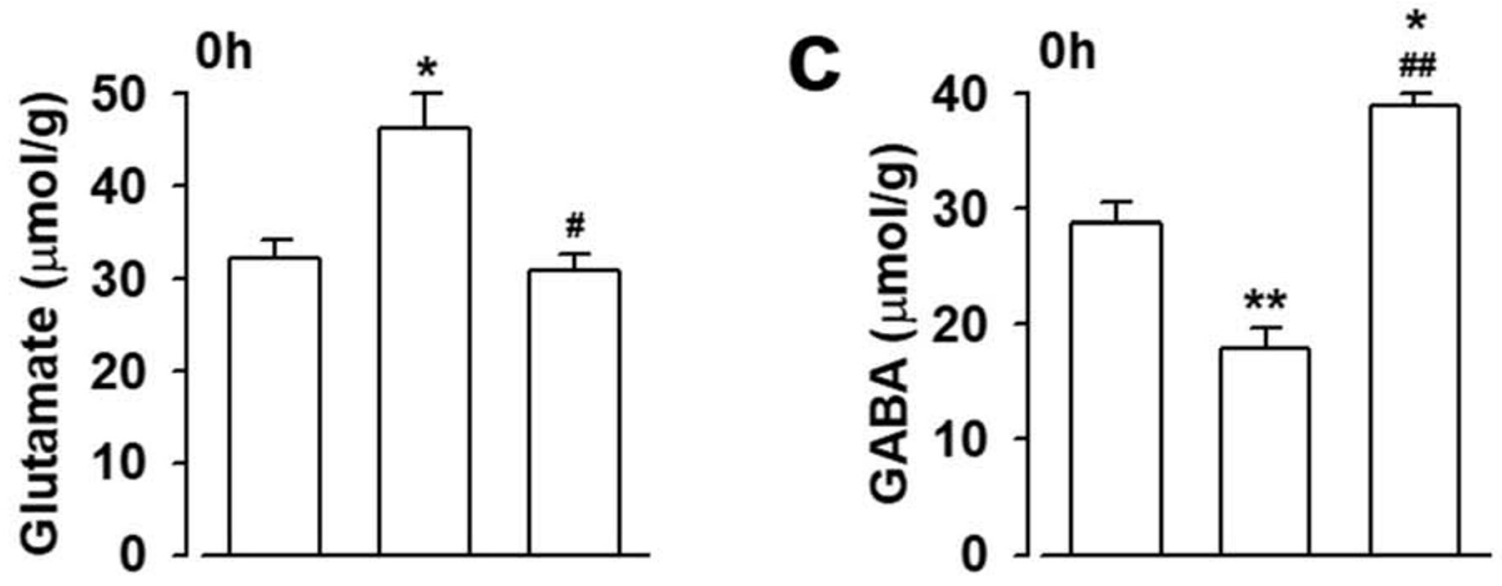

d

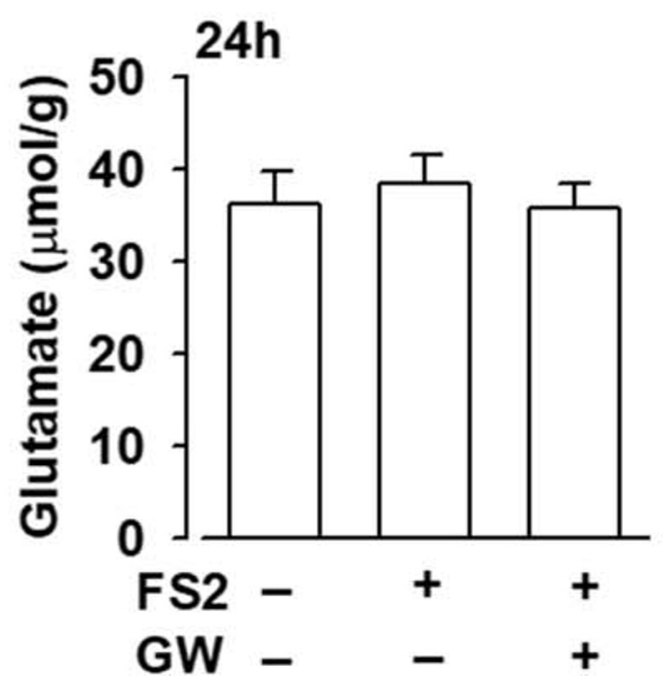

E

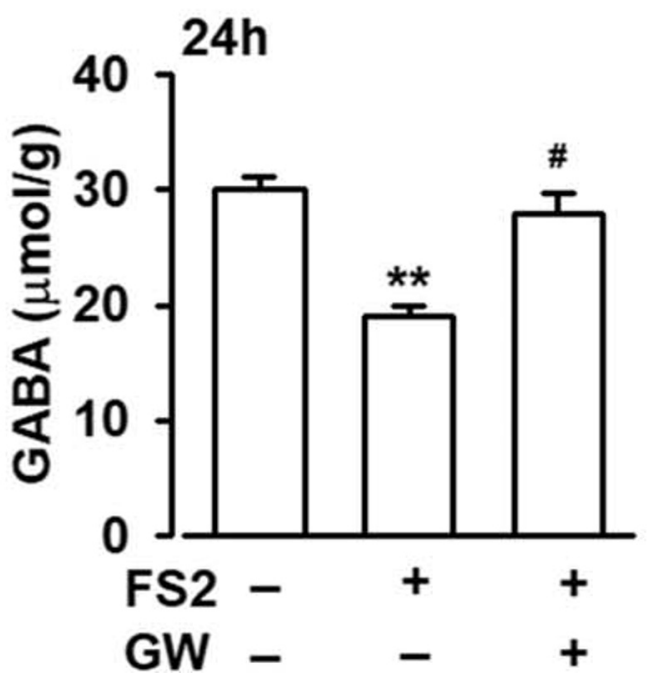


Fig. 6 The effects of GW3965 on endogenous glutamate and GABA in mouse amygdala. Mouse amygdala from each group were collected and subjected to high-performance liquid chromatography (HPLC) analysis. (a) Representative elution time of glutamate and GABA by HPLC assay. The concentrations of (b) glutamate and (c) GABA in the amygdala were determined immediately after last stimuli with or without GW3965 (GW, $10 \mathrm{mg} / \mathrm{kg}$, i.p.) administration. The concentrations of (d) glutamate and (e) GABA in amygdala were determined $24 \mathrm{~h}$ after last stimuli with or without GW $(10 \mathrm{mg} / \mathrm{kg}$, i.p. ) treatment. Error bars represented SEM. $n=$ $4, * p<0.05, * * p<0.01$, versus control group; ${ }^{\#} p<0.05,{ }^{\# \#} p<0.01$, versus FS2 group

anxiolytic effects mediated by GW administration as shown in Fig. 5a, b, and $d$, whereas infection of $\operatorname{shLXR} \beta$ lentivirus abolished the increased time spent in the open arms (Fig. 5a) and entries into the open arms (Fig. 5b) after GW administration, and also prevented the decreased time spent in the central area using OFT in FS2-stressed mice after GW administration (Fig. 5d). Moreover, lentiviral shLXR $\beta$ enhanced FS2-induced anxiety (Fig. 5a, b, d), confirming LXR $\beta$ isoform was involved in anxiety development. However, the number of total arm entries in the EPM (Fig. 5c) and the total distance traveled in the OFT (Fig. 5e) did not significantly differ in each group, indicating that locomotor activity was not affected by lentivirus infection. The data showed that $\operatorname{shLXR} \beta$, which resulted in the reduction of LXR $\beta$ expression in BLA, abolished GWmediated anxiolytic effects, suggesting that GW exerted anxiolytic function through activation of LXR $\beta$ subtype.

\section{The LXRs Agonist GW3965 Corrected the Imbalance of Excitatory/Inhibitory Neurotransmitters in the Amygdala}

Neurotransmission of a certain number and normal function of receptors are responsible for proper information processing. Evidence showed that E/I imbalance contributed to anxiety development [11]; we then detected the levels of two main neurotransmitters, Glu and GABA, in BLA using the HPLC method. HPLC analysis revealed that Glu and GABA were eluted at $8.47 \mathrm{~min}$ and $32.73 \mathrm{~min}$ (Fig. 6a). The levels of Glu and GABA in the amygdala were calculated referring to the standard curve $y=1564.6 x+46,709\left(R^{2}=0.9984\right)$ and $y=$ $1754.2 x+96,891\left(R^{2}=0.9993\right)$. The level of Glu from stressed BLA increased to $46.21 \pm 3.72 \mu \mathrm{mol} / \mathrm{g}$ protein (Fig. $6 \mathrm{~b})$, significantly higher than that of the control group (32.24 $\pm 2.04 \mu \mathrm{mol} / \mathrm{g}$ ) when mice were immediately sacrificed after the last stress. However, there was no significant change of the Glu level when the mice were sacrificed $24 \mathrm{~h}$ after the last stimulus in stressed BLA at $38.50 \pm 3.08 \mu \mathrm{mol} / \mathrm{g}$, compared with the control group at $36.32 \pm 3.47 \mu \mathrm{mol} / \mathrm{g}$ (Fig. 6d).

At the same time, we found that GABA concentration in stressed BLA decreased to $17.98 \pm 1.67 \mu \mathrm{mol} / \mathrm{g}$ immediately after the last stress (Fig. 6c), or $18.97 \pm 1.03 \mu \mathrm{mol} / \mathrm{g}$ at $24 \mathrm{~h}$ after the last stress, which was still significantly lower than that of the control group (Fig. 6e). The result suggested that the acute stress disturbed the balance of E/I neurotransmission in the amygdala. We also found GW administration decreased Glu concentration to $30.81 \pm 1.91 \mu \mathrm{mol} / \mathrm{g}$ (Fig. 6b) and increased GABA level to $38.85 \pm 1.11 \mu \mathrm{mol} / \mathrm{g}$ (Fig. 6c) in stressed BLA immediately after the last stimulus. More importantly, GW administration could maintain GABA level to $27.87 \pm 1.86 \mu \mathrm{mol} /$ $\mathrm{g}$ (Fig. 6e) $24 \mathrm{~h}$ after last stress, which was close to the control group at $30.12 \pm 1.02 \mu \mathrm{mol} / \mathrm{g}$. This data suggested that $\mathrm{GW}$ exerted anxiolytic effects by influencing the neurotransmitters, thus resetting up E/I balance in the amygdala.

\section{GW3965 Administration Reversed the Dysregulation of GABAAR and Glutamate Receptors in Stressed Amygdala}

Receptors of a certain number and normal function are critical for neurotransmitter-mediated various biological functions, the anxiety behaviors induced by acute stress might be associated with the expression changes of GABA and Glu receptors in BLA. GW administration ameliorated E/I imbalance upon acute stress, then, we evaluated the effects of GW on the expression levels of Glu and GABA receptors. GABA $\mathrm{R}$ mediates the inhibitory effects in CNS, especially $\mathrm{GABA}_{\mathrm{A}} \mathrm{R}-\alpha 2$ and $\mathrm{GABA}_{\mathrm{A}} \mathrm{R}-\gamma 2$, which are highly expressed in key regions responsible for pain-related mental disorders including NAc, mPFC, and amygdala. Western blot results showed that acute stress led to the reduction of GABA $_{\mathrm{A}} \mathrm{R}-\alpha 2$ (Fig. 7a, b) and GABA $\mathrm{A}-\gamma 2$ expression (Fig. 7a, c) in BLA. GW administration significantly increased $\mathrm{GABA}_{\mathrm{A}} \mathrm{R}-\alpha 2$ expression to $96.24 \% \pm 5.29 \%$ of control (Fig. $7 \mathrm{a}, \mathrm{b})$ and $\mathrm{GABA}_{\mathrm{A}} \mathrm{R}-\gamma 2$ expression to $92.66 \% \pm 7.13 \%$ of control (Fig. 7a, c).

It is well evidenced that GluR1-containing $\alpha$-amino-3-hydroxy-5-methyl-4-isoxazole-propionic acid (AMPA) receptor plays crucial roles in emotional disorders, especially the phosphorylation of GluR1 at Ser831/Ser845. We found that GW administration reversed the hyperphosphorylation of $\mathrm{p}$ GluR1-831 (Fig. 7d, g) and p-GluR1-845 (Fig. 7d, h) to $125.45 \% \pm 18.43 \%$ of control (Fig. $7 \mathrm{~d}, \mathrm{~g}$ ), and $100.94 \% \pm$ $9.54 \%$ of control (Fig. 7d, h) respectively in the stressed BLA. Meanwhile, N-methyl-D-aspartate (NMDA) receptor is another kind of glutamate receptor responsible for processing the excitatory transmission in CNS. We further found that GW significantly decreased the promoted expression of subtype of NMDAR, NR2B (Fig. 7d, e) and NR2A (Fig. 7d, f) upon acute stress to $166.01 \% \pm 12.38 \%$ (Fig. $7 \mathrm{~d}$, e) and $72.79 \% \pm 8.26 \%$ of control (Fig. $7 \mathrm{~d}$, f) respectively. However, the expression of PSD95 showed no significant changes in each group (Fig. 7d, i). All the collected data indicated that GW administration alleviated anxiety-like behaviors through modulating E/I balance both on neurotransmitters and receptors. 


\section{LXRs Activation Rebalanced the Inhibitory} and Excitatory Synaptic Transmission in the Amygdala of FS2-Stressed Mice

Previous studies evidenced that the imbalance of excitatory and inhibitory synaptic transmission in BLA contributes to the emergence of anxiety [14]. To demonstrate the possible mechanisms of LXR $\beta$ in stress-induced anxiety, the expression pattern of LXR $\beta$ in the amygdala was checked first. The immunofluorescence results showed that LXR $\beta$-positive neurons were mainly distributed in glutamatergic neurons (Fig. 8a1-a4) and moderately in GABAergic neurons (Fig. 8b1-b4), suggesting that LXR $\beta$ may function in regulating synaptic transmission in the amygdala. Further, the mEPSC and mIPSC, which reflect the release of a

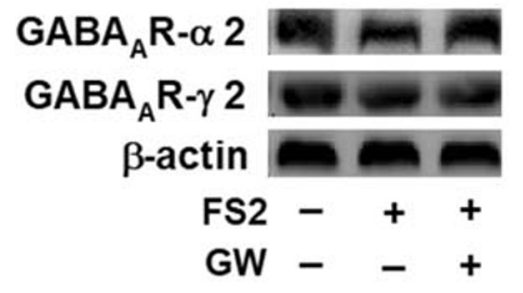

d

NR2B

NR2A

p-GluR1-831

p-GluR1-845

GluR1

PSD95

$\beta$-actin

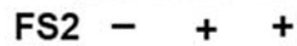

GW - -+ b

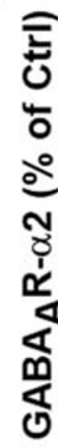

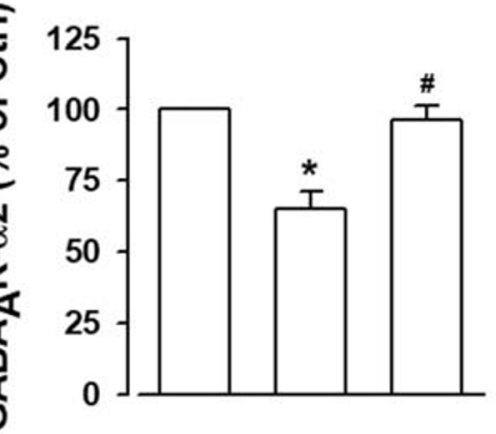
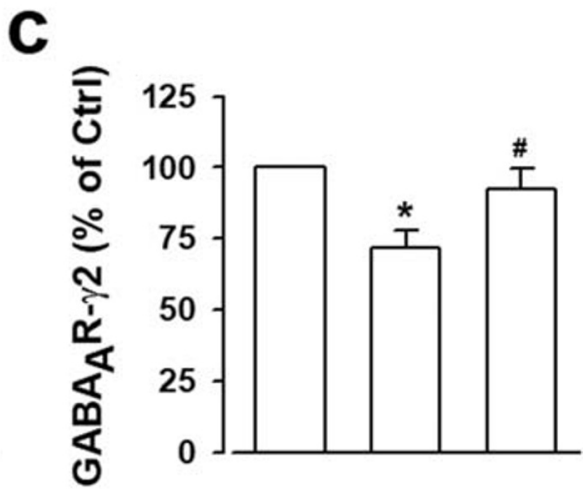

e

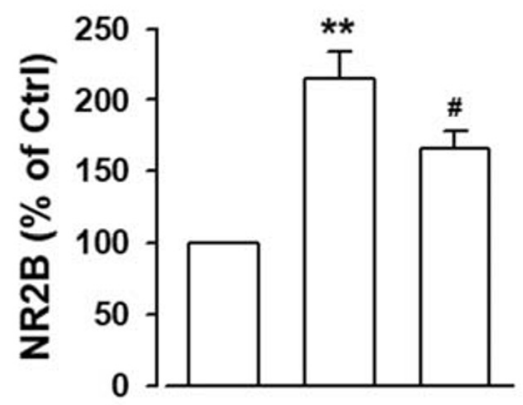

f

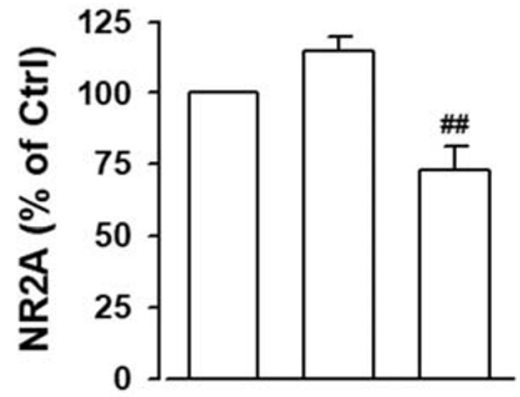

g

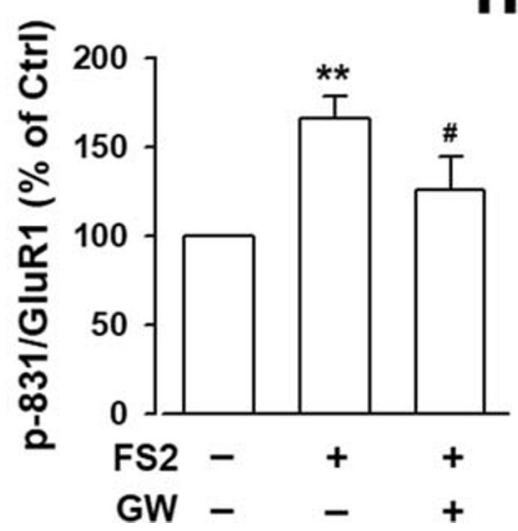

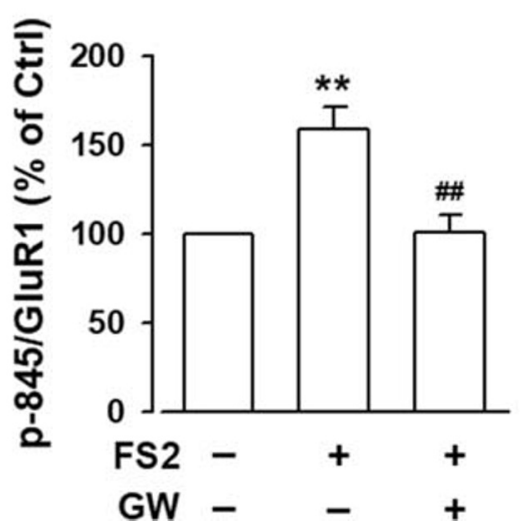

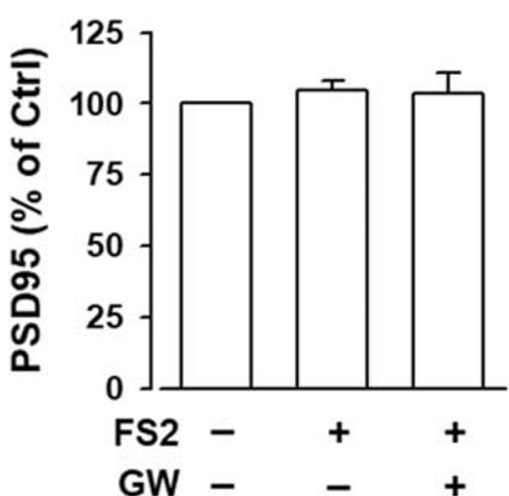

Fig. 7 The effects of GW3965 on the expression changes of $\mathrm{GABA}_{\mathrm{A}} \mathrm{R}$ and glutamate receptors in stressed amygdala. (a) Representative Western blot results showing the expression levels of $\mathrm{GABA}_{\mathrm{A}} \mathrm{R}-\alpha 2$ and $\mathrm{GABA}_{\mathrm{A}} \mathrm{R}-\gamma 2$ subtypes under FS2 stress in the BLA of mice with or without $\mathrm{GW} 3965(\mathrm{GW}, 10 \mathrm{mg} / \mathrm{kg}$, i.p.) administration. The intensity of (b) $\mathrm{GABA}_{\mathrm{A}} \mathrm{R}-\alpha 2$ and (c) $\mathrm{GABA}_{\mathrm{A}} \mathrm{R}-\gamma 2$ subtypes was normalized with endogenous $\beta$-actin and expressed as percent change compared with control. (d) Representative Western blot results showing the expression levels of NR2B, NR2A, phosphorylated GluR1 at S831/845 (p-GluR1831/845), GluR1 and PSD95 in control, FS2, and FS2+GW groups. The intensity of (e) NR2B, (f) NR2A, (g) p-GluR1-831, (h) p-GluR1-845, and (i) PSD95 expression was normalized with endogenous $\beta$-actin and expressed as percent change compared with control. Error bars represented SEM. $n=4, * p<0.05,{ }^{* *} p<0.01$, versus control group; ${ }^{\#} p<0.05$, ${ }^{\# \#} p<0.01$, versus FS2 group 
single quanta of neurotransmitter, in pyramidal neurons from BLA were recorded. Both the amplitude and frequency of mEPSC were significantly increased in neurons from FS2stressed BLA compared with the control group (Fig. 9). However, GW incubation $(10 \mu \mathrm{M})$ for 20 min could reverse the strengthened mEPSC frequency (Fig. 9a, b, d) and elevated amplitude induced by FS2 stress (Fig. 9a, c, e). These findings provided evidence that GW perfusion inhibited the excitatory glutamatergic neurotransmission which was involved in anxiety development through LXRs activation.

It is well evidenced that GluR1-containing AMPA receptors play crucial roles in emotional disorders, especially the phosphorylation of GluR1 at Ser831/Ser845. We further found that $G W$ administration reversed the hyperphosphorylation of GluR1 at Ser831 and Ser845 (Fig. $7 \mathrm{~d}, \mathrm{~g}, \mathrm{~h}$ ) in mice amygdala upon FS2 stress. mIPSCs were also recorded in pyramidal neurons of the BLA. The amplitude (Fig. 10a, b, d) and frequency (Fig. 10a, c, e) of mIPSCs dramatically decreased in the BLA from FS2-stressed mice, and GW incubation reversed the above changes (Fig. 10). These results are consistent with the HPLC results and imply that the anxiolytic effects of LXRs activation is related to the increased inhibitory presynaptic release in the BLA.

\section{Discussion}

In the current study, we have shown that FS2 stress resulted in the reduction of LXR $\beta$ expression in mice amygdala, and LXR $\beta$ activation by $\mathrm{GW}$ offered anxiolytic effects through rebalancing the $\mathrm{E} / \mathrm{I}$ neurotransmission by modulating neurotransmitters and receptors of Glu and GABA in the FS2-stressed anxiety model. Electrophysiological analysis further confirmed that LXR $\beta$ activation corrected the enhanced $\mathrm{mEPSC}$ and reduced mIPSC upon acute stress, thus alleviating anxiety-like behaviors. Taken together, our results suggest LXR $\beta$ may represent a potential novel target for the treatment of anxiety and also provide a novel insight into the underlying mechanisms of anxiety.

The balance of excitatory and inhibitory synaptic transmission is crucial for proper information processing, depending on the optimal function of a certain number of neurotransmitters, Glu and GABA, as well as their corresponding receptors. Therefore, the changes of these neurotransmitters could reflect the variation of E/I. The disturbance of E/I balance during mental processing, enhanced excitatory transmission, or reduced inhibitory transmission resulted in anxiety-like behaviors [25]. Evidence showed that increased Glu release and decreased reabsorption was associated with the increased E/I ratio [26], while increased GABA led to a decrease in E/I [27]. At the same time, the $\mathrm{mEPSC} / \mathrm{mIPSC}$ frequency recorded by the whole-cell patch clamp is often used as an indicator of E/I balance [28]. In fact, the amplitude and frequency $\mathrm{mEPSC} / \mathrm{mIPSC}$ recorded in isolated brain slices are often used to reflect $\mathrm{E} / \mathrm{I}[29,30]$. And $\mathrm{E} / \mathrm{I}$ balance measured by $\mathrm{mEPSC}$ and
mIPSC is a physiological proxy for the relative timing and magnitude of excitation versus inhibition [31]. In this study, the changes of E/I were investigated by detecting neurotransmitters and receptors, and recording $\mathrm{mEPSC} / \mathrm{mIPSC}$ by whole-cell patch clamp, and data showed that GW could restore the E/I balance through modulation of the factors above.

Several brain regions account for the pathogenesis of anxiety, and the amygdala has been evidenced as a key part implicated in the acquisition and expression of anxiety under stress. Short-term or long-term exposure to stress can induce hyperactivity of amygdala-associated anxiety experiences. The amygdala contains abundant local GABA interneurons and GABAergic projection neurons [32], and the glutamatergic neurons are firmly regulated by a comparatively small population of GABAergic inhibitory neurons within the amygdala $[11,13]$. The hyperactivity and hyperresponsiveness of the amygdala induced by stress is always accompanied by the removal of inhibitory control governed by GABAergic interneurons [14]. Threatening stress-induced the attenuation of GABAergic neurotransmission in BLA, and compelling evidence showed decreased GABAergic activation in BLA after rats suffered shock. In the state of anxiety, BLA inhibitory neurons continue to increase their discharge, suggesting these GABAergic neurons are hence adequately positioned to play a central role in the regulation of stress. Moreover, an increasing ratio of Glu/ GABA is presumed to represent the activation of the related brain regions under stress [14]. Therefore, correcting or reversing the neurotransmitter release may correct abnormal behavioral changes. In the present study, we found the level of Glu increased and GABA reduced in FS2-stressed BLA after the last force swimming by HPLC analysis, and the decreased GABA level still had a statistical significance after $24 \mathrm{~h}$ later (Fig. 6). The data further demonstrated that GW administration could correct the abnormal levels of Glu and GABA in the stressed BLA, this may reveal the anxiolytic effects of GW. The potential mechanisms that GW affected the levels of Glu and GABA after stress need to be elucidated. It is wellaccepted that the regulation of neurotransmitters involves its synthesis, release, and transport. Evidence showed that GW, an agonist for LXRs, affected Glu release and transport by regulating related proteins, resulting in the reduced Glu level [33]. LXRs are ligand-activated transcription factors and exert critical roles in the development of neurological diseases as important regulators of transcription. Some target genes of LXRs are associated with promoting neurological recovery [34], as well as genes involved in the clearance of amyloid $\beta$-protein [35]. Therefore, this transcriptional regulation of LXRs provides a possibility of Glu synthesis. Meanwhile, the glutamate decarboxylase, which is responsible for GABA synthesis, was decreased in LXR $\beta$ knockout mice [36], suggesting the potential mechanism that activating LXR $\beta$ enhances GABA production related to glutamic 
dehydrogenase. Definitely, more studies are needed to provide evidence to support these possibilities.

The neuroreceptor system, including AMPAR, NMDAR, and others, is actively involved in anxiety induction, which was evidenced by their antagonists evoking anxiolytic-like responses under stressful conditions [37]. At the same time, the different $\mathrm{GABA}_{\mathrm{A}} \mathrm{R}$ subunits in BLA of the amygdala have been reported to modulate the behavioral responses deriving from stressful conditions as major inhibitory neuronal system [38]. We further observed that the expression levels of Glu receptors including NR2B, NR2A, p-GluR1-831 and pGluR1-845 increased obviously in the stressed BLA (Fig. 7). GABA receptors, responsible for the inhibitory transmission process, are divided into three classes including $\mathrm{GABA}_{\mathrm{A}} \mathrm{R}, \mathrm{GABA}_{\mathrm{B}} \mathrm{R}$, and $\mathrm{GABA}_{\mathrm{C}} \mathrm{R}$. GABA $\mathrm{A}$ is a ligandgated ion channel, and subunits $G_{A B A} R-\alpha 2$ and $\mathrm{GABA}_{\mathrm{A}} \mathrm{R}-\gamma 2$ are mainly linked to anxiety development. We found that the expression levels of $\mathrm{GABA}_{\mathrm{A}} \mathrm{R}-\alpha 2$ and $\mathrm{GABA}_{\mathrm{A}} \mathrm{R}-\gamma 2$ were decreased in FS2-stressed BLA (Fig. 7), and GW administration also corrected the promoted Glu receptors expression and decreased $\mathrm{GABA}_{\mathrm{A}}$ receptors expression (Fig. 7). Our results indicated that GW-mediated LXR activation offered anxiolytic effects (Fig. 3), which was closely related to the improvement of GABA, the decrease of Glu neurotransmitter and the correction of abnormal expression of receptors. This confirmed the contribution of E/I disequilibrium to the functioning of the amygdala and GW rebuilt E/I balance for anti-anxiety.

The neural and molecular basis of these stress-induced behavioral abnormalities currently remains unclear. Previous work has also shown that alterations in the amygdala gene expression are associated with stress-induced alterations in mouse anxiety-like behavior. As transcription factors, LXRs have emerged as important regulators controlling cellular and whole-body cholesterol homeostasis [39]. Cholesterol is a main component in the CNS synapse for genesis and is essential for optimal neurotransmitter release [40]. Herein, we speculated that LXR $\beta$ may participate in the mechanism of stressinduced anxiety in the brain. We found FS2 stress resulted in a reduction of LXR $\beta$ expression in the BLA, whereas LXR $\alpha$ levels remained unchanged regardless of the stress stimuli (Fig. 2), implying that $L X R \beta$ but not $L X R \alpha$ may be associated with the etiology of stress-induced anxiety. Given LXR $\beta$ deletion led to abnormal development and function of CNS, degeneration of motor neurons and dopaminergic neurons, activation of microglia and astrogliosis beyond lipid accumulation [41]. RNAi method was applied to knock down LXR $\beta$ expression in BLA (Fig. 4), and knockdown of LXR $\beta$ in the BLA by shRNA infection facilitated mice anxiety-like behaviors under stress (Fig. 5), indicating that LXR $\beta$ is critical in maintaining
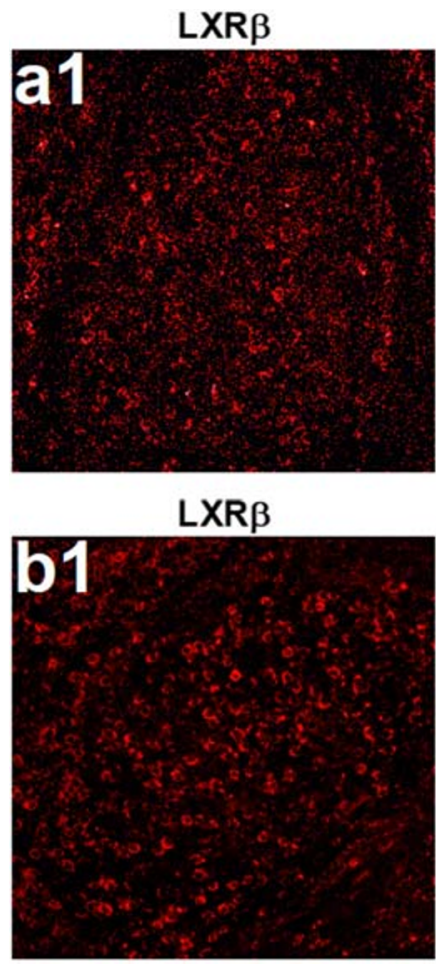

Fig. 8 The cellular pattern of LXR $\beta$ colocalization in mice amygdala. The brain slices containing the amygdala were stained for (a) CAMKII $\alpha+$ LXR $\beta$. (b) GAD67 + LXR $\beta$. LXR $\beta$ colocalized mainly with glutamatergic neurons (CAMKII $\alpha$ positive), moderately with
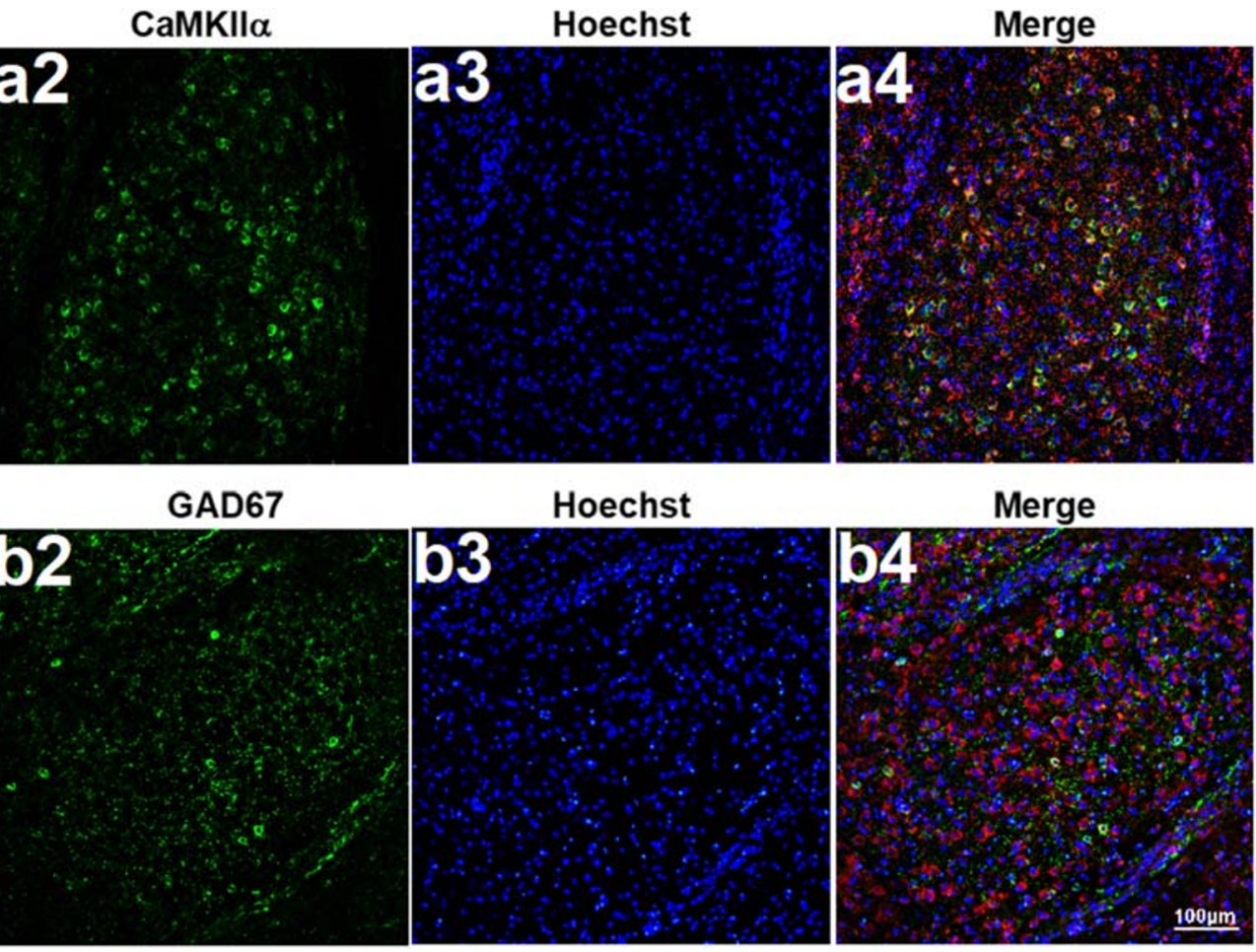

GABAergic neurons (GAD67 positive) in the amygdala. CAMKII $\alpha$ and GAD67 showed in green, LXR $\beta$ showed in red, and Hoechst in blue. Scale bars $=100 \mu \mathrm{m}$ 
mental processing. This data is consistent with a previous study [18]. Due to the lack of specific agonist for LXR $\beta$ isoform,

GW3965, an $\operatorname{LXR} \alpha / \beta$ dual agonist, was administrated to evaluate the exact isoform of LXRs (LXR $\alpha$ or LXR $\beta)$ by which GW-mediated anxiolytic effects using the stressinduced anxiety model. Our data showed that GW alleviated

a

Ctrl

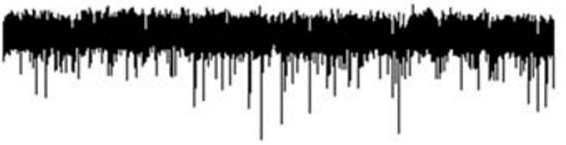

b

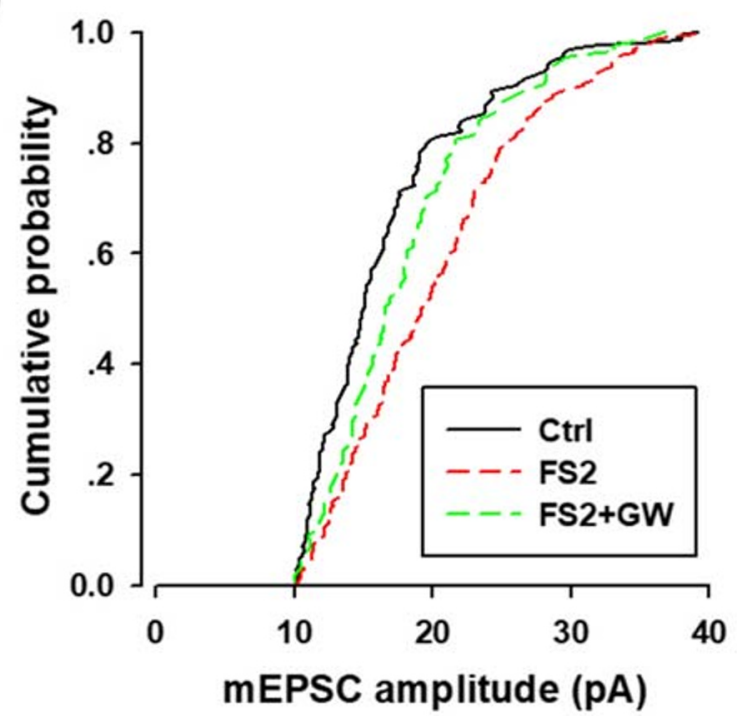

d

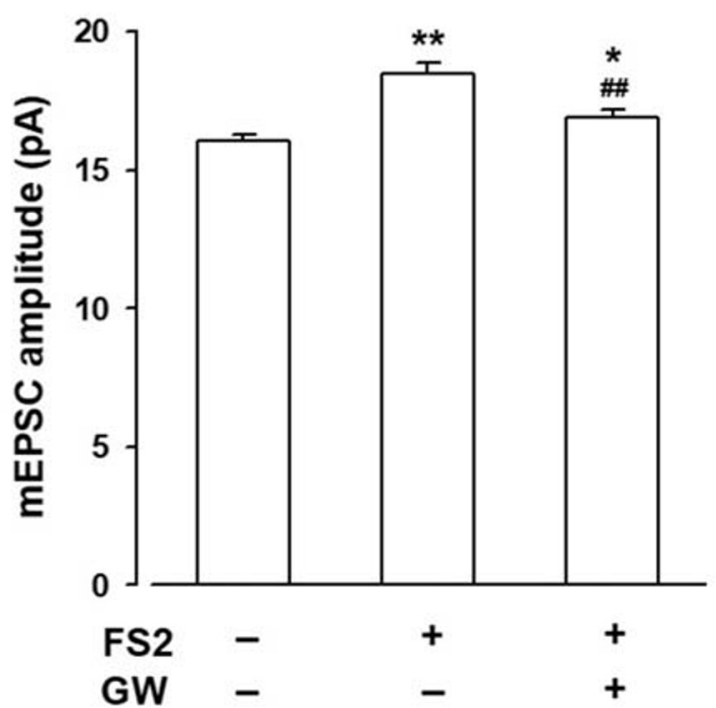

Fig. 9 GW3965 treatment abolished the enhanced mEPSC amplitude in FS2-stressed mice amygdala. (a) The sample showed the mEPSCs in pyramidal neurons of the BLA in each group. (b) Cumulative amplitude and (c) frequency histogram of mEPSCs from the slices in different groups. The amplitude (d) and frequency (e) of mEPSCs were statistically analyzed in each group. The amplitude and frequency of mEPSCs were
FS2

FS2+GW

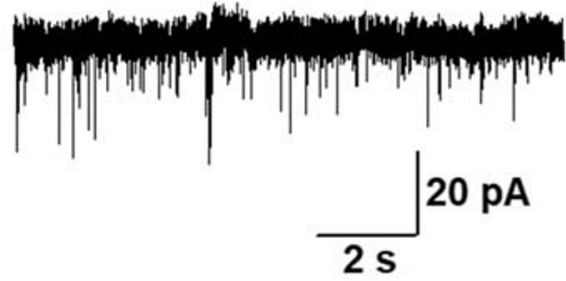

C

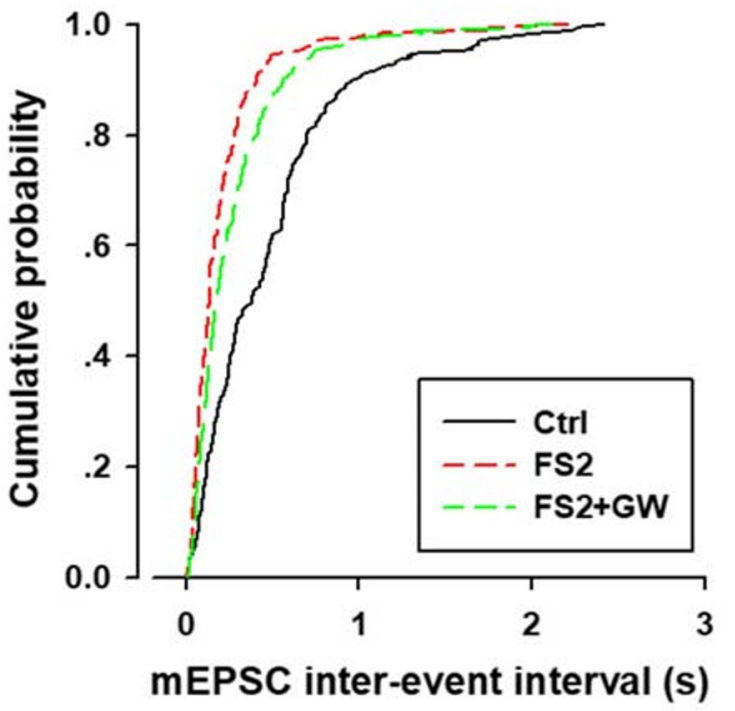

e

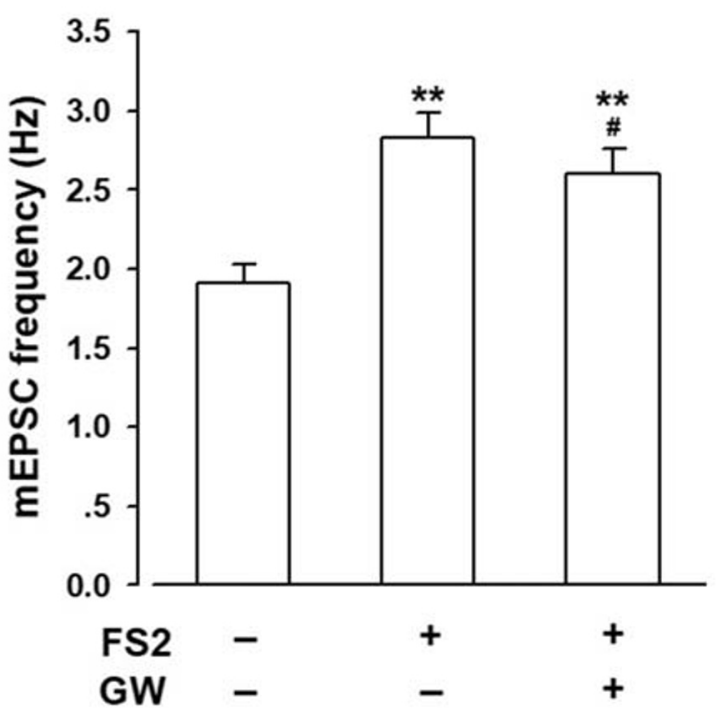

remarkably increased in the BLA of model mice compared with control ones, perfusion of GW3965 $(10 \mu \mathrm{M})$ for 20 min could significantly reverse the amplitude and the frequency of mEPSCs in the BLA of model mice. All graphs represented mean \pm SEM. $n=8$ neurons $/ 4$ mice, ${ }^{*} p<0.05,{ }^{* *} p<0.01$, versus control group; ${ }^{\#} p<0.05,{ }^{\# \#} p<0.01$, versus FS2 group 
the anxiety-like behaviors upon stress insult. Moreover, we confirmed that it was isoform LXR $\beta$ that mediated the anxiolytic effects of GW (Fig. 5); this shed light on the crucial role of
LXR $\beta$ in the development of anxiety, and LXR $\beta$ activation may represent a potential novel target for the treatment of anxiety.

a

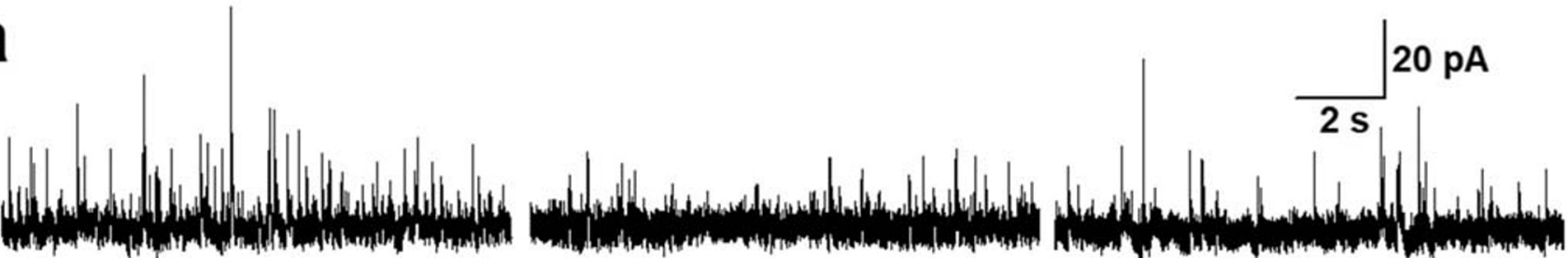

Ctrl

b

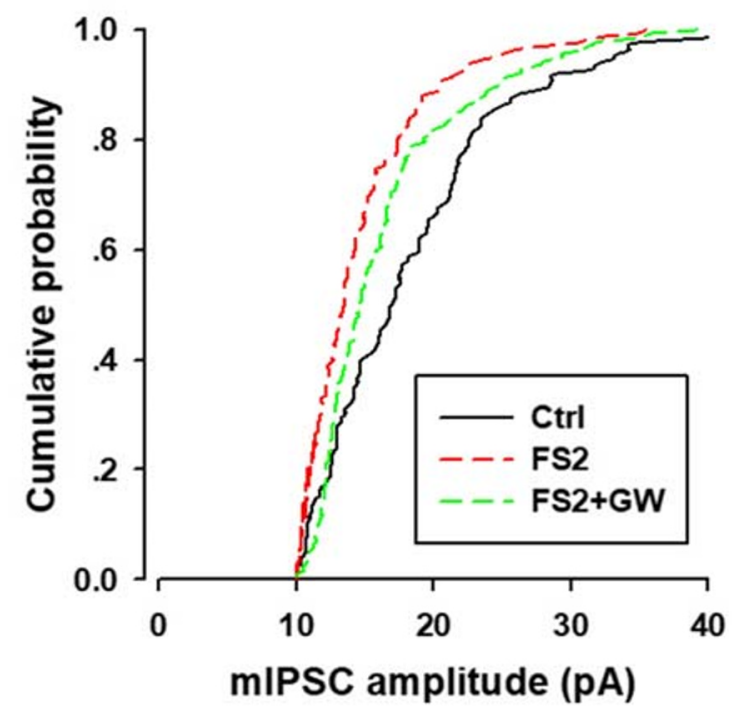

d

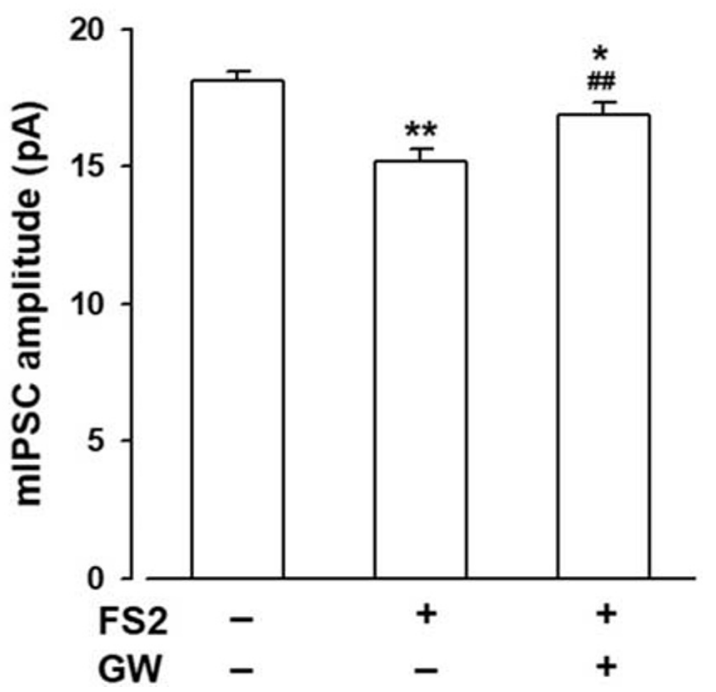

Fig. 10 GW3965 treatment enhanced inhibitory presynaptic release in the BLA of model mice. (a) The sample showed the mIPSCs in pyramidal neurons of the BLA in each group. (b) Cumulative amplitude and (c) frequency histogram of MIPSCs from the slices in different groups. The amplitude (d) and frequency (e) of mIPSCs were statistically analyzed in each group. The amplitude and frequency of
FS2

FS2+GW

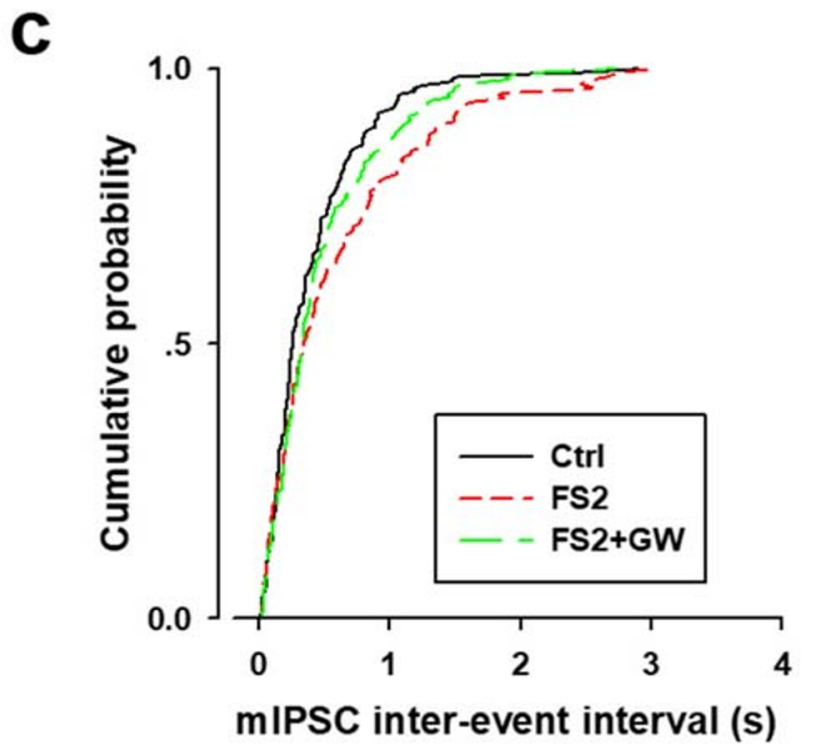

$\mathbf{e}$

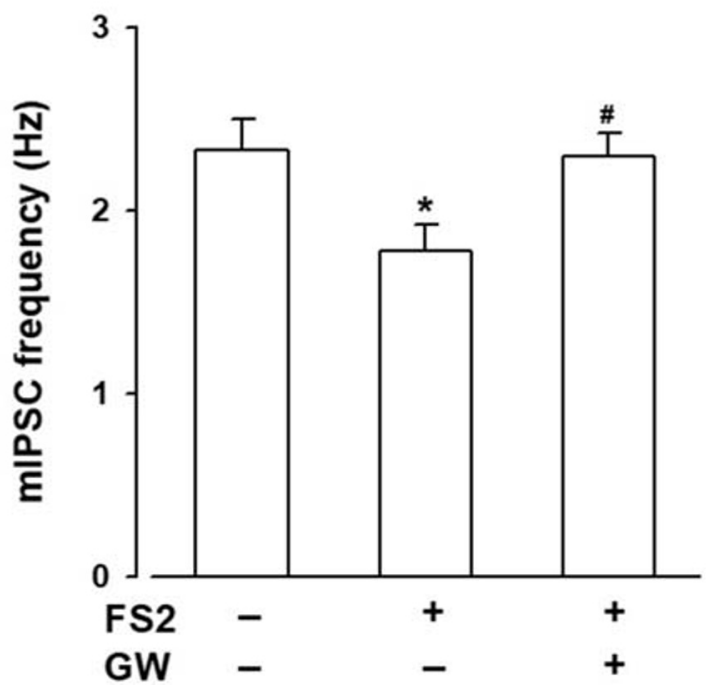

mIPSCs decreased significantly in the BLA of model mice compared with the control group, perfusion of GW $(10 \mu \mathrm{M})$ for 20 min could reverse both the amplitude and the frequency of mIPSCs in the BLA of model mice. Error bars represented SEM. $n=8$ neurons $/ 4$ mice, ${ }^{*} p<0.05,{ }^{*} p<0.01$, versus control group; ${ }^{\#} p<0.05,{ }^{\# \#} p<0.01$, versus FS2 group 
Previous studies reported that anxiety in female $\operatorname{LXR} \beta^{-/}$ mice with loss of glutamic acid decarboxylase in mPFC [36]. However, the exact function of LXR $\beta$ in the anxiety has not been verified. We observed that LXR $\beta$ were expressed in both glutamatergic and GABAergic neurons (Fig. 8), providing the possibility that LXR $\beta$ may regulate E/I synaptic transmission in the amygdala, thus affecting E/I balance. Electrophysiology recording was further performed to investigate the influence of LXR $\beta$ on neuron function. The electrophysiological data revealed the amplitude and frequency of mEPSC were significantly increased in neurons from FS2-stressed BLA, and this enhancement was reversed by GW administration (Fig. 9). Phosphorylation of GluA1 at the S831 and S845 sites contributes to the enhancement of excitatory transmission. We further found that GW administration reduced the expression levels of p-GluR1-831/845; this definitely was ascribed to the anxiolytic effects of GW. However, the amplitude and frequency of mIPSCs dramatically decreased in the stress BLA along with the reduction of $\mathrm{GABA}_{\mathrm{A}} \mathrm{R}$ subunit $\alpha 2$ and $\gamma 2$ in our experiments after FS2-induced stress, which was reversed by LXR $\beta$ activation (Fig. 10). The data indicated that GW increased the inhibitory presynaptic release, thus augmenting BLA GABAergic neurotransmission. LXR $\beta$ expressed in neurons influences neural function responsiveness upon stress insult, and LXR $\beta$ is also expressed in glial cells as evidenced [22], and the full impact of LXR $\beta$ on stress-induced anxiety needs be addressed in further study.

Collectively, our results described the synaptic function of LXR $\beta$ in the amygdala and uncovered the attenuation of LXR $\beta$ in the BLA in stressed mouse brain which resulted in presynaptic impairment of E/I synaptic transmission. Importantly, intact inhibitory synaptic transmission and proper E/I balance were required for the optimal functioning in the responsiveness of amygdala neurons to stress. Furthermore, this E/I disequilibrium in the BLA was associated with impaired expression of corresponding receptors and impaired behaviors of the animals in the EPM and OFT under stress. Current data contribute to future progress in finding novel therapeutic approaches, including LXR $\beta$ agonist, for stress-related anxiety disorders.

Acknowledgments This work was supported by the Key International Cooperation Projects of Shaanxi Province (No. 2020KWZ-021), the Military Medicine Promotion Projects (No. 2018jsts09) for Prof Wu, the National Natural Science Foundation of China (No. 81571328 for Prof Wu, No. 81701352 for Dr. Li, and No. 81771469 for Dr. Liu), and the Research Foundation from the Social Development Science and Technology Project of Shaanxi Province (No. 2020JQ-464) for Mr. Wang.

\section{References}

1. Mah L, Szabuniewicz C, Fiocco AJ. Can anxiety damage the brain? Curr Opin Psychiatry 2016;29(1):56-63.

2. McLean CP, Asnaani A, Litz BT, et al. Gender differences in anxiety disorders: prevalence, course of illness, comorbidity and burden of illness. J Psychiatr Res 2011;45(8):1027-35.
3. Gold AL, Morey RA, McCarthy G. Amygdala-prefrontal cortex functional connectivity during threat-induced anxiety and goal distraction. Biol Psychiatry 2015;77(4):394-403.

4. Yang L, Wang M, Guo YY, et al. Systemic inflammation induces anxiety disorder through CXCL12/CXCR4 pathway. Brain Behav Immun 2016;56:352-62.

5. Pitman RK, Rasmusson AM, Koenen KC, et al. Biological studies of post-traumatic stress disorder. Nat Rev Neurosci 2012;13(11): 769-87.

6. Bryant RA, Kemp AH, Felmingham KL, et al. Enhanced amygdala and medial prefrontal activation during nonconscious processing of fear in posttraumatic stress disorder: an fMRI study. Hum Brain Mapp 2008;29(5):517-23.

7. Liu W, Ge T, Leng Y, et al. The Role of Neural Plasticity in Depression: From Hippocampus to Prefrontal Cortex. Neural Plast 2017;2017:6871089.

8. McEwen BS, Nasca C, Gray JD. Stress Effects on Neuronal Structure: Hippocampus, Amygdala, and Prefrontal Cortex. Neuropsychopharmacology 2016;41(1):3-23.

9. Pitkanen A, Savander V, LeDoux JE. Organization of intraamygdaloid circuitries in the rat: an emerging framework for understanding functions of the amygdala. Trends Neurosci 1997;20(11):517-23.

10. Janak PH, Tye KM. From circuits to behaviour in the amygdala. Nature 2015;517(7534):284-92.

11. Prager EM, Bergstrom HC, Wynn GH, et al. The basolateral amygdala gamma-aminobutyric acidergic system in health and disease. $\mathrm{J}$ Neurosci Res 2016;94(6):548-67.

12. Klausberger T, Somogyi P. Neuronal diversity and temporal dynamics: the unity of hippocampal circuit operations. Science 2008;321(5885):53-7.

13. Diaz MR, Chappell AM, Christian DT, et al. Dopamine D3-like receptors modulate anxiety-like behavior and regulate GABAergic transmission in the rat lateral/basolateral amygdala. Neuropsychopharmacology 2011;36(5):1090-103.

14. Jie F, Yin G, Yang W, et al. Stress in Regulation of GABA Amygdala System and Relevance to Neuropsychiatric Diseases. Front Neurosci 2018;12:562.

15. Theofilopoulos S, Wang Y, Kitambi SS, et al. Brain endogenous liver $\mathrm{X}$ receptor ligands selectively promote midbrain neurogenesis. Nat Chem Biol 2013;9(2):126-33.

16. Fan X, Kim HJ, Bouton D, et al. Expression of liver X receptor beta is essential for formation of superficial cortical layers and migration of later-born neurons. Proc Natl Acad Sci U S A 2008;105(36): $13445-50$

17. Wang L, Schuster GU, Hultenby K, et al. Liver X receptors in the central nervous system: from lipid homeostasis to neuronal degeneration. Proc Natl Acad Sci U S A 2002;99(21):13878-83.

18. $\mathrm{Xu} \mathrm{P}, \mathrm{Xu} \mathrm{H}$, Tang $\mathrm{X}$, et al. Liver X receptor beta is essential for the differentiation of radial glial cells to oligodendrocytes in the dorsal cortex. Mol Psychiatry 2014;19(8):947-57.

19. Suarez-Roca H, Leal L, Silva JA, et al. Reduced GABA neurotransmission underlies hyperalgesia induced by repeated forced swimming stress. Behav Brain Res 2008;189(1):159-69.

20. Liu P, Che X, Yu L, et al. Uridine attenuates morphine-induced conditioned place preference and regulates glutamate/GABA levels in $\mathrm{mPFC}$ of mice. Pharmacol Biochem Behav 2017;163:74-82.

21. Chen Y, Duan Y, Kang Y, et al. Activation of liver X receptor induces macrophage interleukin-5 expression. J Biol Chem 2012;287(52):43340-50.

22. Li YJ, Zhang K, Sun T, et al. Epigenetic suppression of liver X receptor beta in anterior cingulate cortex by HDAC5 drives CFAinduced chronic inflammatory pain. J Neuroinflammation 2019;16(1):132.

23. Azogu I, Plamondon H. Inhibition of TrkB at the nucleus accumbens, using ANA-12, regulates basal and stress-induced orexin A 
expression within the mesolimbic system and affects anxiety, sociability and motivation. Neuropharmacology 2017;125:129-45.

24. Pechtel P, Pizzagalli DA. Effects of early life stress on cognitive and affective function: an integrated review of human literature. Psychopharmacology (Berl) 2011;214(1):55-70.

25. Stefanits H, Milenkovic I, Mahr N, et al. GABAA receptor subunits in the human amygdala and hippocampus: Immunohistochemical distribution of 7 subunits. J Comp Neurol 2018;526(2):324-48.

26. Guerriero RM, Giza CC, Rotenberg A. Glutamate and GABA imbalance following traumatic brain injury. Curr Neurol Neurosci Rep 2015;15(5):27.

27. Deidda G, Bozarth IF, Cancedda L. Modulation of GABAergic transmission in development and neurodevelopmental disorders: investigating physiology and pathology to gain therapeutic perspectives. Front Cell Neurosci 2014;8:119.

28. Bridi MCD, Zong FJ, Min X, et al. Daily Oscillation of the Excitation-Inhibition Balance in Visual Cortical Circuits. Neuron 2020;105(4):621-9 e4.

29. Dong Z, Chen W, Chen C, et al. CUL3 Deficiency Causes Social Deficits and Anxiety-like Behaviors by Impairing ExcitationInhibition Balance through the Promotion of Cap-Dependent Translation. Neuron 2020;105(3):475-90 e6.

30. Han S, Tai C, Westenbroek RE, et al. Autistic-like behaviour in Scn1a+/- mice and rescue by enhanced GABA-mediated neurotransmission. Nature 2012;489(7416):385-90.

31. Froemke RC. Plasticity of cortical excitatory-inhibitory balance. Annu Rev Neurosci 2015;38:195-219.

32. Spampanato J, Polepalli J, Sah P. Interneurons in the basolateral amygdala. Neuropharmacology 2011;60(5):765-73.

33. Baez-Becerra C, Filipello F, Sandoval-Hernandez A, et al. Liver X Receptor Agonist GW3965 Regulates Synaptic Function upon
Amyloid Beta Exposure in Hippocampal Neurons. Neurotox Res 2018;33(3):569-79.

34. Cui X, Chopp M, Zacharek A, et al. The neurorestorative benefit of GW3965 treatment of stroke in mice. Stroke 2013;44(1):153-61.

35. Jiang Q, Lee CY, Mandrekar S, et al. ApoE promotes the proteolytic degradation of Abeta. Neuron 2008;58(5):681-93.

36. Tan XJ, Dai YB, Wu WF, et al. Anxiety in liver X receptor beta knockout female mice with loss of glutamic acid decarboxylase in ventromedial prefrontal cortex. Proc Natl Acad Sci U S A 2012;109(19):7493-8.

37. Bi LL, Wang J, Luo ZY, et al. Enhanced excitability in the infralimbic cortex produces anxiety-like behaviors. Neuropharmacology 2013;72:148-56.

38. Poulter MO, Du L, Zhurov V, et al. Plasticity of the GABA(A) receptor subunit cassette in response to stressors in reactive versus resilient mice. Neuroscience 2010;165(4):1039-51.

39. Peet DJ, Turley SD, Ma W, et al. Cholesterol and bile acid metabolism are impaired in mice lacking the nuclear oxysterol receptor LXR alpha. Cell 1998;93(5):693-704.

40. Mauch DH, Nagler K, Schumacher S, et al. CNS synaptogenesis promoted by glia-derived cholesterol. Science 2001;294(5545): 1354-7.

41. Sacchetti P, Sousa KM, Hall AC, et al. Liver X receptors and oxysterols promote ventral midbrain neurogenesis in vivo and in human embryonic stem cells. Cell Stem Cell 2009;5(4):409-19.

Publisher's Note Springer Nature remains neutral with regard to jurisdictional claims in published maps and institutional affiliations. 